\title{
Dynamics of Individual Income Rank Volatility: Evidence from West Germany and the US
}

\author{
${ }^{1}$ University of Luxembourg, Esch-sur-Alzette 4366, Luxembourg, E-mail: anne.hartung@uni.lu. \\ https://orcid.org/0000-0001-5865-9404, https://orcid.org/0000-0002-3802-7597. \\ ${ }^{2}$ Sapienza University of Rome, Roma RM 00185, Italy. https://orcid.org/0000-0001-7944-3813.
}

\begin{abstract}
:
This paper presents a methodology for comparing income rank volatility profiles over time and across distributions. While most of the existing measures are affected by changes in marginal distributions, this paper proposes a framework based on individuals' relative positions in the distribution that is neutral to structural changes that occur in that distribution. Applying this approach to West Germany and the US over three decades, we show that while poorer individuals in both countries are the most volatile in all periods investigated, the long-term trends of volatility at the different points of the distribution in each of these countries differ.
\end{abstract}

Keywords: rank volatility, income, risk, inequality, middle class, West Germany, US

JEL classification: D31, J6, I30

DOI: 10.1515/bejeap-2018-0153

In recent decades, rising inequality in many industrialized countries has been a disquieting fact that has prompted a renewed interest in understanding distributional dynamics. At the same time, a large number of studies have shown that instability of individual earnings or incomes is also high and has significantly increased contributing to the exacerbation of disparities between individuals and households (Moffit and Zhang 2018; Bania and Leete 2009; Comin, Groshen, and Rabin 2009; Dahl, DeLeire, and Schwabish 2011; Dyan, Elmendorf, and Sichel 2012; Gottschalk and Moffitt 2002; Gottschalk and Moffitt 2009; Shin and Solon 2011). Most studies are based on earnings or incomes and use aggregate measures of instability, such as alternative estimators of transitory variance and volatility. ${ }^{1}$ However, income or earning based measures of volatility are affected by changes in the marginal distributions of the reference variable, such as changes in income inequality from one period to the other, that we call structural changes. Moreover, the use of aggregate measures hides the possible countervailing effects of volatility over the entire distribution. This paper contributes to the existing literature with respect to these two features.

Specifically, this paper focuses on instability in relation to the rank of individuals within a society rather than on the instability of their incomes or earnings. An individual's rank is defined by his relative position within the distribution of household income as opposed to the distribution of labor earnings. There are several appealing features of the rank based approach. ${ }^{2}$ First, using ranks instead of income levels allows focusing on comparisons that are independent from the marginal distributions since these are transformed into a common uniform one. Hence, our methodology is not affected by the structural changes that occur in the distribution. ${ }^{3}$ This is relevant because, for instance, in periods of sustained variations in inequality, income changes can be seriously affected by such structural transformations (see Jenkins and Van Kerm 2006; Van Kerm 2004). Therefore, our framework allows for an assessment of volatility that is generated by the real movements of individuals within the distribution and not by the structural changes of the distribution. Hence, ranks represent a stable benchmark in contrast to incomes that are fluctuating mechanically in times of inequality variations.

Our framework does not require the estimation of a formal model of income dynamics. We measure individual volatility by applying the magnitude of the change in individual income ranks rather than by isolating the transitory components of those changes. In this respect, our methodology can be considered a complementary approach to the Gottschalk-Moffitt procedure. The use of a "descriptive approach", such as the one applied here does not enable transitory shocks to be disentangled from permanent ones. However, the results obtained do not depend on underlying assumptions about the income generating process (see Moffitt and Gottschalk 2012; Shin and Solon 2011).

Besides these advantages also different theories, such as Easterlin's theory of relative utility (Easterlin 1974) as well as the positional goods framework, substantiate the importance of ranks. Higher positions within an income distribution, rather than absolute income, lead to utility gains compared with reference wages (Clark,

Anne Hartung is the corresponding author.

All authors share equal contribution

(c))BY-NC-ND $(2019$ Chauvel et al., published by De Gruyter.

This work is licensed under the Creative Commons Attribution-NonCommercial-NoDerivatives 4.o License. 
Kristensen, and Westergard-Nielsen 2009). Models of relative concerns differentiating between ordinal approaches (rank) and cardinal approaches (distance to the mean income) reason similarly. Hopkins (2008) argues that ranks are crucial to understand the role of inequality for individual well-being as the effect of others' income changes may vary across the income distribution. Volatility of ranks is moreover useful from the perspective of relative deprivation, which claims that subjective deprivation of not having something is an increasing function of the proportion of those who do have it (Yitzhaki 1979). In other words, it is the change in ranks relative to others that matters, as both cardinal and ordinal income losses or gains are not fully interpersonally comparable but it is much more difficult to agree on the meaning of a change in the levels of income than on a change in income ranks only. This reflects the traditional social choice theory issues of preferring welfare rankings to interpersonally comparable cardinal welfare functions, which are undoubtedly more data intensive when it comes to the empirical application (Sen 1976).

The second contribution of our approach is the focus on individual or disaggregate measures of volatility as opposed to the use of aggregate measures. The latter may lead to unsatisfactory results because they may hide countervailing volatility and volatility trends across the distribution. Hence, we argue for the need to develop an alternative methodology based on profiles of individual volatility. Such profiles and their trends can be asymmetric, that is, they may have differential impacts on different sections of the distribution. One reason for this is that institutions affect the stability of income careers, and job flexibility usually hits those individuals occupying the lowest positions in the income distribution harder than those positioned higher up.

A number of recent studies have begun to explore individual heterogeneity within this trend. Considering the US experience, Dyan, Elmendorf, and Sichel (2012) find that volatility rose in the early 1970s as well as in the late 2000s, and that this widening of the income distribution was a phenomenon especially related to changes in the tails of the distribution. In view of the comparably high volatility of household incomes at the extreme ends of the income distribution, Hardy and Ziliak (2013) allude to a "wild ride" experienced at the top and bottom of the distribution. Such heterogeneity also finds support in the work of Bania and Leete (2009), who demonstrate that US volatility was highest for lower income households and that their instability showed a sharper increase than that of other groups during the 1990s. Gottschalk (1997) finds that in the US, the probability of remaining within the lowest quintile was lower than that of remaining within the top quintile.

For West Germany, several studies find an increasing trend of volatility in the end of the 1990s, which continues in the early 2000s (Bartels and Bönke 2013; Bönke, Giesecke, and Lüthen 2015; Daly and Valletta 2008; Myck, Ochmann, and Qari 2009). Bartels and Bönke (2013) and Bönke, Giesecke, and Lüthen (2015) show in their in-depth analyses of men's earnings that earnings volatility rose particularly for low-income earners. Technological change and a more globalized economy reduce the demand for the low-skilled and lead thus to income dispersion in this group (Bönke, Giesecke, and Lüthen 2015). Bartels and Bönke (2013) suggest that rising earnings volatility is cushioned by risk-sharing households and welfare states such that net household income volatility remained stable over time. Comparing Germany and the US, redistribution and risk insurance provided by the welfare state are more pronounced in the former than in the latter, levelling out earnings volatility to a greater extent than in the US (cf. Chen 2009).

However, most of these studies are either based on income levels, as opposed to ranks, or they consider large-scale units such as quintiles that ignore intra-group volatility. Therefore, in contrast to previous studies, we investigate the heterogeneity of income rank volatility across a distribution, adopting a volatility profile. ${ }^{4}$ The elimination of the marginal income distribution's impact - through the use of income rank - makes it possible to compare volatility levels and trends across countries regardless of their level of inequality. Hence, being our methodology not affected by the stretching-out of the distribution, which is specific of each country, allows us to gain comparability (Bar-Haim et al. 2018; Bar-Haim, Chauvel, and Hartung 2019).

Using the ranks related to the household income distribution rather than the ranks related to the earning distribution, we subscribe to the view that while changes in the earning distribution are exclusively related to labor market dynamics, the broader concept of income also incorporates the role of the welfare state and family dynamics in absorbing negative events. Instability can be costly for individuals, but the extent of its undesirability depends on individual risk preferences, risk pooling possibilities, and levels of insurance available against the risk of income losses. Social protection, income transfers, and the labor supply within households provide such income-smoothing insurance. Therefore, in this context, the use of household income to identify an individual's rank in the socioeconomic hierarchy appears to be a more appropriate methodological choice compared with approaches based on earnings (see Jenkins 2011). More precisely, we use the logit transformation of ranks (hereafter, logitrank), which permits the establishment of proportionality between rank volatility and volatility of a specifically defined relative income, the medianized income, thereby enabling estimation problems at the boundaries to be solved.

We apply our framework to evaluate individual income rank volatility and its trend in West Germany and the US between 1983 and 2009 and demonstrate its relevance by revisiting an ongoing debate on comparisons of volatility in these two countries (e. g. Gottschalk and Spolaore 2002). The point of departure for our study 
is the observation that, when using a volatility measure based on income ranks, the US is not ranked as being more volatile than Germany, contrary to received wisdom. Furthermore, a comparison between these two countries is appropriate, because in addition to being characterized by intrinsically different economic and political structures, they have exhibited different levels of inequality and inequality dynamics in recent decades. Our study reveals the following findings. First, those who were relatively poor experienced much higher volatility than those who were richer in both countries. Second, the poor were found to be less volatile in West Germany compared with the poor in the US. Third, the volatility gap between the poor and the rich tended to decline in West Germany but not in the US. Last, while volatility increased consistently in the US for the lower middle class, it remained quite stable in West Germany.

Thus, the contribution of our study is twofold. The first is methodological, as we introduce a framework for evaluating distributional profiles of individual income rank volatility. In doing so, we are able to observe volatility trends that are net of structural changes. Hence, our paper contributes to the arsenal of tools used to assess individuals' income dynamic over time (see, inter alia, Grimm 2007; Van Kerm 2009; Palmisano and Van de Gaer 2016, 2016; Palmisano and Peragine 2015) but that are only focused on evaluating the volatility of incomes - not of ranks. The second contribution is empirical as we provide new insights on volatility trends that have prevailed in West Germany and the US in the last decades.

The rest of the paper is organized as follows. Section 1 introduces the methodology. Section 2 presents the empirical results. Section 3 offers our conclusions.

\section{Methodological Framework}

Let a society's income distribution at time $t$ be represented by the cumulative distribution function (cdf) $F$ : $R_{+} \rightarrow[0,1]$. Hence, $F\left(y_{t}\right)=P\left(\tilde{y_{t}} \in R_{+}: \tilde{y_{t}} \leqslant y_{t}\right)$, that is, the cdf returns the probability $p_{t} \in[0,1]$ of observing income that is less or equal to $\tilde{y_{t}}$ in that society at time $t$, with $t=1, \ldots, T$. The ranks of individuals in this society can then be defined by $p_{t}=F\left(y_{t}\right)$.

The logit transformation of the income rank (the logitrank) can then be expressed as follows:

$$
\operatorname{logit}\left(p_{t}\right)=\ln \left(\frac{p_{t}}{\left(1-p_{t}\right)}\right)
$$

This transformation of the concerned variable allows for a more accurate estimation of the volatility experienced by individuals situated at the tails of the distribution. The use of ranks per se implies that while those individuals positioned in the center of the distribution can move in two directions (up or down), those positioned at the bottom (or top) of the distribution can only move in one direction, up (or down). The logit transformation enables us to overcome this drawback. Thus, in contrast to the use of percentile ranks, our framework does not accord greater importance to movements at the center. When an individual with rank $p=0.99$ gets richer, substantial income movement has weak effects in terms of rank variation but not in terms of logitrank variation. In addition, the logitrank is an equivalent measure to the log of the medianized income (Chauvel 2016). Table 1 shows the conversion between logitranks and percentile ranks, which is useful for interpreting the results. For instance, a magnitude of -2 relates to quantile 0.119 , close to the first decile, while a magnitude of 2 relates to an income 2.7 times higher than the median.

Table 1: Magnitudes of logitrank and percentile ranks.

\begin{tabular}{|c|c|c|c|c|c|c|c|c|c|c|c|}
\hline Logitr & -5 & -4 & -3 & -2 & -1 & 0 & 1 & 2 & 3 & 4 & 5 \\
\hline Rank & 0.007 & 0.018 & 0.047 & 0.119 & 0.269 & 0.500 & 0.731 & 0.881 & 0.953 & 0.982 & 0.993 \\
\hline
\end{tabular}

${ }^{1}$ Source: Authors' calculations.

We subsequently use logitranks to describe and visualize income rank volatility and its changes over time. Let us denote the average logitrank of individuals between $T$ periods as follows, with $T \geqslant 2$ :

$$
\overline{\log i t(p)}=\frac{1}{T} \sum_{t=1}^{T} \log i t\left(p_{t}\right)
$$

For the sake of simplicity, we refer to eq. (2) as an intertemporal logitrank. 
We measure individual volatility as the standard deviation of logit $\left(p_{t}\right)$, which reflects the intensity/magnitude of moves, or the instability of a position. Individual income rank volatility can then be defined as follows:

$$
v(\overline{\operatorname{logit}(p)})=\sqrt{\frac{1}{T} \sum_{t=1}^{T}\left(\operatorname{logit}\left(p_{t}\right)-\overline{\log i t(p)}\right)^{2}}
$$

Figure 9 describes the logitrank variations in Germany and the US between 1983 and 2009. Plotting eq. (3) against each $\overline{\log i t(p)}$, we obtain volatility profiles as shown in Figure 8 in the Appendix and in Figure 2-Figure 4 reported in the following sections. This graphical tool provides intuitive information on the extent of income rank volatility across the distribution.

The advantage of this logitrank-based measure of volatility is that it is not affected by changes in inequality over space or time. When there is a rise in inequality, and if the intrinsic volatility regime remains constant, the log of the medianized income-based measure of volatility correspondingly increases as a trivial consequence. By contrast, the logitrank-based volatility is not affected by distributional changes. This is because its construction is net of any inequality transformation.

Applying this procedure, we can simply transform the empirical quantile function of any distribution in its vertical projection. In the case of panel analysis for two or more years, the logitrank transformation consists in the reshaping of the empirical distributions on an invariable reference distribution. This implies that logitrankbased volatility absorbs all structural transformations, retaining the sole exchange mobility. ${ }^{5}$ Given our focus on pure volatility, the application of this approach enables to conduct meaningful comparisons over time and across countries. ${ }^{6}$

Moreover, the use of descriptive statistics and more elaborate models based on logitrank as a dependent variable is appropriate, because logitranks are simple linear transformations of the log of incomes. Therefore, apart from the difference between these two kinds of models, entailed in the fact that logitrank variations are depurated from structural changes, working with the former is equivalent to working with the latter. Furthermore, as for any other ranking strategy, we dispose of a fixed point - relative position with respect to the rest of the distribution - that cannot be obtained when using incomes.

Indeed, other measurement frameworks of social mobility abstract from structural changes through the use of a benchmark distribution in which individuals are assigned the final period income associated with their rank in the initial period, such as the transition matrix provides. However, in such frameworks, the use of income quantiles leads to the loss of some fine detail. The logit transformation of ranks that we adopt in this paper (cf. Bar-Haim et al. 2018; Bar-Haim, Chauvel and Hartung 2019), instead, allows for a more accurate estimation of volatility at the tails of the distribution. As discussed above, when individuals with highest (lowest) ranks get richer (poorer), sizable income variations have weak effects in terms of rank variation but not in terms of logitrank variation.

Our approach also entails other appealing technical features. First, existing rank-based studies on the volatility of incomes or earnings have often examined quintile (or decile) transitions over varying time periods (e. g. Gottschalk 1997). However, this method is unable to differentiate between the magnitudes of changes in income ranks. Thus, for example, it treats changes from the 19th to the 21st percentile in the same way as it treats transitions from the 1st to the 39th percentile. Our framework, based on a continuum of ranks, is able to account for distance. A further advantage of this framework is that it is not dominated by small changes in income levels near zero that usually lead to huge or infinite changes when a methodology entailing the log of income is applied.

It deserves to be noticed, however, that our method works best with very large panel datasets providing higher case numbers also in the tails of the distribution. To which point in the tails the observations should be limited remains therefore an empirical question.

\section{Individual Income Rank Volatility Profiles for West Germany and the US}

\subsection{Data}

Our empirical analysis is based on the panel component of the Cross National Equivalent File (CNEF, Frick et al. 2007, 2008), which provides harmonized data for (West) Germany (SOEP) and the US (PSID), representative of the respective resident populations. We consider biannual waves ${ }^{7}$ available for both countries between 1983 and 2009. ${ }^{8}$ We restrict our US sample to African Americans and Caucasian Americans, excluding other racial groups such as Asians and Hispanics because of the later start of these subsamples. For the same reason, we 
exclude East Germany and the SOEP subsample of high-income households. In line with the literature, we restrict our sample to individuals aged between 20 and 65, for reasons of comparability with existing analyses. However, robustness checks on the sample of individuals of all ages are discussed at the end of this section.

To measure individual income rank volatility, we attribute the equalized annual disposable household income to each individual. Disposable household income includes income after transfers and the deduction of income tax and social security contributions. It is the sum of the total household income from the labor earnings of all household members, asset flows, private retirement income, private transfers, public transfers, and social security pensions net of total household taxes. Incomes are expressed in constant 2010 prices and are adjusted for differences in household size dividing them by the square root of the household size. Individual volatility is measured over a 2-year period. The use of only two points in time allows capturing the short-term variability of future income. ${ }^{9}$

We use sample weights to compute all estimates with confidence intervals obtained through 500 bootstrap replications.

\subsection{Logitrank Volatility Profiles}

The above properties and the particular shapes of the volatility profiles shown in Figure 8 let us to estimate a volatility profile for Germany and US as follows:

$$
\ln (v(\overline{\operatorname{logit}(p)}))=\beta_{0}+\beta_{1} \overline{\operatorname{logit}(p)}+\beta_{2} \overline{\operatorname{logit}(p)}_{\mid}^{2}{ }_{\log i t(p)<0}+\beta_{3} \overline{\operatorname{logit}(p)}_{\mid \operatorname{logit}(p)>0}^{2}+\varepsilon
$$

Volatility profiles are estimated with a polynomial in which the log of the logitrank volatility is expressed as a function of the intertemporal logitrank and its square. To account for dissymmetry, we collapse the curvatures $\left(\beta_{2}\right.$ and $\left.\beta_{3}\right)$ in two parameters located, respectively, below and above the median (logitrank $=0$ ). Figure 1 illustrates our conceptualization of estimated volatility profiles developed using eq. (4).

As shown in Figure 1, estimating profiles of volatility through eq. (4) is very useful as it allows capturing relevant information related to the income dynamics under analysis. These are the constant $\beta_{0}$ that catches volatility near the median, the slope $\beta_{1}$ that denotes the degree to which volatility is higher (or lower if $\beta_{1}<0$ ) at the top than at the bottom, and $\beta_{2}$ and $\beta_{3}$ that express the degree of increase of volatility at the extremes of the distribution $\left(\beta_{2}>0\right.$ or $\left.\beta_{3}>0\right)$. Therefore, variations in the three parameters provide interpretable information on the increase or decrease of volatility in specific parts of the distribution. A positive change in $\beta_{0}$ implies that volatility increases for all parts. A rise in the value of $\beta_{1}$ indicates more volatility for the richest individuals. Finally, higher values of $\beta_{2}$ and $\beta_{3}$ indicate more volatility for extreme values (and relatively higher stability at the median level). Consequently, we are able to better understand in which part of the distribution income rank volatility increases or decreases disproportionally.

The volatility profile can be considered as a complementary tool to better understand changes in distributions and may enrich the arsenal of existing tools, such as the income mobility profiles or the growth incidence curves, that have been recently proposed by the literature (see, among others, Van Kerm 2009; Grimm 2007; Palmisano and Peragine 2015; Palmisano 2018; Palmisano and Van de Gaer 2016). However, while existing tools consider either the first or the final period distribution as the reference one to analyze individuals' income movements and use income as the variable of interest, our approach uses both initial and final period distribution as the reference one, hence introducing a multitemporal perspective, and focuses on rank rather than on income. An extension to income is also provided in the empirical section for comparative purpose.

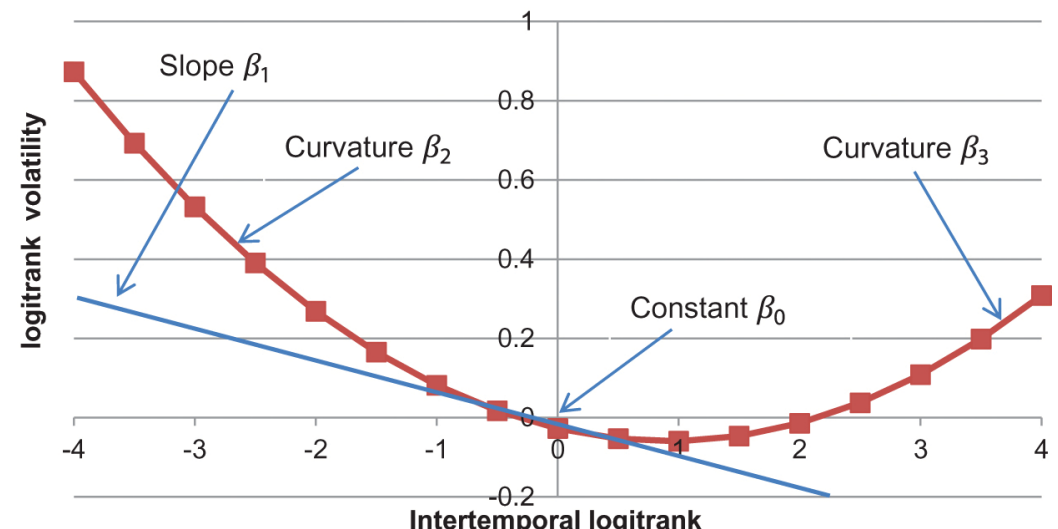

Intertemporal logitrank 
Figure 1: Profile of volatility

Note: For the conversion between logitranks and percentile ranks see Table 1.

Source: Authors' illustration.

\subsection{Results}

Figure 2 shows the estimated profiles of income rank volatility for West Germany and the US over the entire study period. The volatility profiles for both countries appear to be U-shaped. This particular shape is neither a natural nor a trivial outcome of our methodology. It denotes greater changes, on average, at the bottom and at the top of the distribution compared with the changes occurring at the center of the distribution. An important feature of the U-shaped curvature characterizing the volatility profiles depicted in Figure 2- Figure 4 is its asymmetry. This indicates that in both countries, the middle-income classes have been, and continue to be, more stable than the top-income classes, whereas the top-income classes are still more stable than those at the bottom of the income hierarchy.

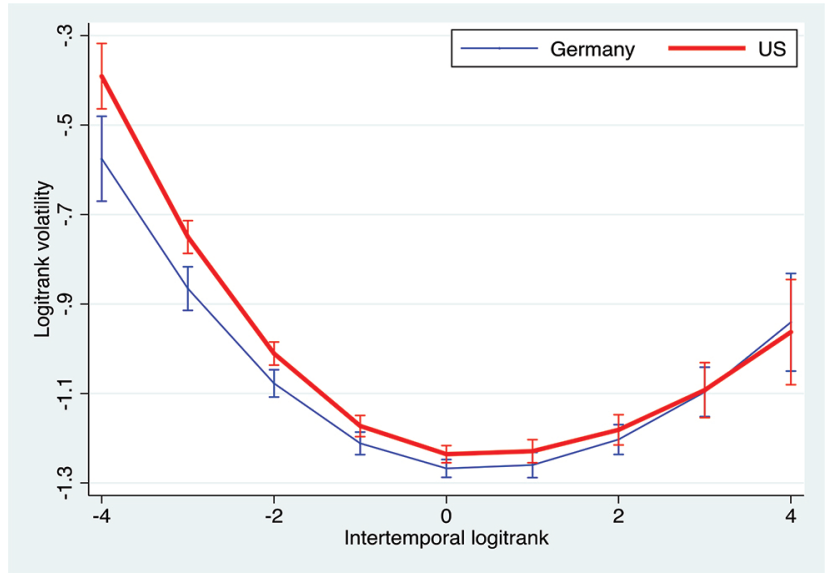

Figure 2: Logitrank volatility profiles in West Germany and the US, 1983-2009.

Notes: Volatility including $95 \%$ convidence intervals depicted on the y-axis is estimated using eq. (6). Intertemporal logitrank refers to eq. (4). For the conversion between logitranks and percentile ranks see Table 1.

Source: Authors' computations based on the CNEF.

The 95\% confidence intervals in Figure 2 indicate furthermore that the overall regimes of logitrank-based volatility for West Germany and the US differ for the poorest 12\% (between logitrank -2 and -4 ) between 1983 and 2009 but not for the largest part of the distribution. This result partly corroborates previous studies suggesting that West Germany was a relatively mobile society, and especially prior to reunification (e. g. Bayaz-Ozturk, Burkhauser, and Couch 2014; Maasoumi and Trede 2001). Conversely, our findings do not corroborate previous results suggesting that household income volatility (log-income) was higher in the US than in Germany with the exception of the poorest (see Gottschalk and Spolaore 2002; Van Kerm 2004). Indeed, Figure 2 shows that the intrinsic systems of volatility (net of distributional changes) in Germany and the US do not differ significantly for the largest part of the distribution between 1983 and 2009.

Over time, changes in this asymmetry reveal different trends for incomes situated near the median, the top, and the bottom of the distribution. Figure 3 compares Germany and the US over shorter time intervals. During the earlier period (1983-1995, panel on the left), the volatility profiles of the two countries overlap at logitrank -2 , furthermore they never diverge significantly from each other. Conversely, a significant divergence is observed during the subsequent period (1997-2009, panel on the right), with volatility being higher in the US than in Germany for the middle and lower part of the distribution (between logitrank 0 and -3 ).
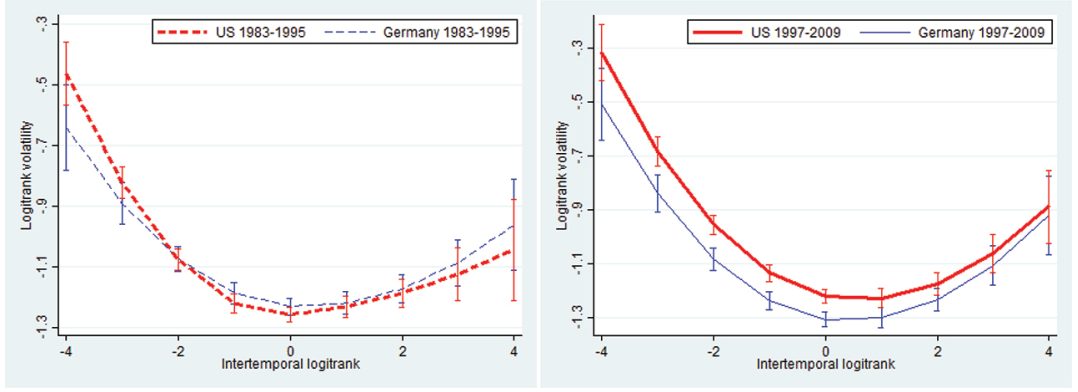
Figure 3: Logitrank volatility profiles in 1983-1995 (left) and 1997-2009 (right): Germany versus the US. Notes: Volatility including $95 \%$ convidence intervals depicted on the y-axis is estimated using eq. (6). Intertemporal logitrank refers to eq. (4). For the conversion between logitranks and percentile ranks see Table 1.

Source: Authors' computations based on the CNEF.

More insights on volatility can be gained by exploring if and how these profiles have changed over time in each of these two countries, as reported in Figure 4. In the US, the lower quarter of the distribution with the exception of the lowest $5 \%$ has become more volatile over time. In contrast, we observe stability for this part of the population in West Germany. Even more, volatility is significantly lower today than in the past for those individuals ranked in the middle of the distribution. Volatility in the tails, on the contrary, has increased although not significantly.

From a methodological viewpoint, it is interesting to compare all the four volatility profiles: Germany 19831995, Germany 1997-2009, US 1983-1995, US 1997-2009 (Figure 10 in the Appendix). There is a frequent overlapping of the profiles between logitrank 2 and logitrank 4 , so that the volatility experience of the upper middle class does not differ substantially between the two countries and the two periods compared. What marks the difference is the volatility trend of the middle and lower part of the distribution. The German poor and the US poor in the past were less volatile than the US poor today. Moreover, the volatility of the lower part of the distribution experienced in the US between 1997 and 2009 is the highest. On the contrary, the upper middle class in Germany in this period is the least volatile when comparing these four profiles. From the bottom $10 \%$ to the median (logitrank -2 to 0), volatility is significantly higher in US between 1997 and 2009 than in all the other cases. Last, we observe that Germany in the past was significantly less volatile than the US today at logitrank -4 , the bottom $2 \%$ of the distribution, implying that it makes sense to extend the analysis at the at the tails of the distribution.

The estimated coefficients of eq. (4), shown in Table 2 in the Appendix and plotted in Figure 2-Figure 4, provide a more precise and insightful depiction of the nature of changes in volatility. As the dependent variable is volatility, higher coefficients indicate greater positive impacts on volatility, while negative coefficients indicate negative impacts. With respect to $\beta_{0}$, which refers to the extent of volatility at the median of the income distribution, the positions of West Germany and the US are reversed during the two study periods $(-1.258$ in the first period and -1.218 in the second period for US, -1.231 in the first period and -1.305 in the second period for West Germany). While West Germany appears to be more volatile than the US near the median during the period prior to 1996, the US becomes more volatile and West Germany much less volatile during the period after 1996 compared with the previous situation (a decrease in $\beta_{0}$ ).
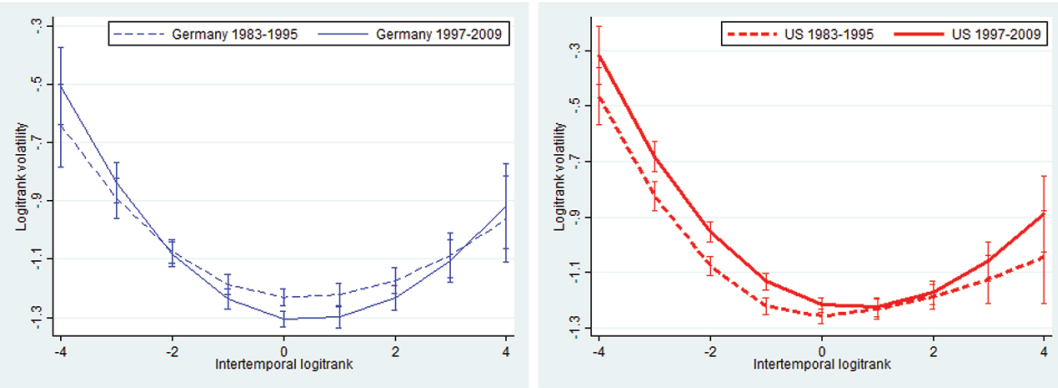

Figure 4: Logitrank volatility profiles in Germany (left) and the US (right), 1983-1995 versus 1997-2009.

Notes: Volatility including $95 \%$ convidence intervals depicted on the y-axis is estimated using eq. (6), but the log of the log-medianized income volatility is used as the dependent variable. Intertemporal logitrank refers to eq. (4). For the conversion between logitranks and percentile ranks see Table 1.

Source: Authors' computations based on the CNEF.

Regarding $\beta_{1}$, which captures the extent of volatility differential between the poorer and the richer, Table 2 shows in each case a negative coefficient - with the exception of the US in the earlier period ( 0.017 in the first period and -0.038 in the second period for US, -0.010 in the first period and -0.024 in the second period for West Germany). In other words, income rank volatility is in these cases on average higher among the poor than among the rich. The decrease in coefficients between the two periods in both countries, but especially in the US, suggests an extensive change in the balance of volatility between the rich and the poor, at the expense of the latter group, especially in the US.

Lastly, $\beta_{2}$ and $\beta_{3}$ indicate the weight of volatility in the tails of the distribution. These second order coefficients describe the (quadratic) curvature at the bottom and top of the distribution, respectively. That is, they depict the deviation of volatility at the extreme ends compared with the median. The first coefficient, $\beta_{2}$, appears to be consistently higher in the US than in West Germany, implying that higher volatility occurred at the bottom compared to the median of the distribution in the US as opposed to West Germany (0.054 and 0.047 in 
the US compared with 0.035 and 0.044 in Germany). By contrast, the second coefficient, $\beta_{3}$, is higher in West Germany (0.019) than in the US (0.009) during the first period, whereas it is almost the same in the two countries higher during the latter period ( 0.030 in both the US and West Germany). However, if the entire period is considered, it is lower in the US (0.020) than in West Germany (0.025). This indicates that volatility at the top, as compared to the bottom, increased in both countries, but more so in the US.

In sum, these results confirm that the volatility gap between the poor and the rich tends to decline in West Germany, in contrast to the US, and that the difference between the volatility experiences of the two countries is clearly related to the volatility trend of the lower-middle class. In a nutshell, the German winners in terms of income stability belong specifically to the middle class. While income risks decline for this income group, lower class Americans face increasing instability. This has occurred in a context of declining relative incomes in this income group compared with the American median, because of increasing inequality within the US. The West-German middle class seems to experience a double gain, whereas the same class in the US experiences a double loss in terms of both poverty and economic insecurity. The general patterns in these two countries evidenced during this latter period seem to confirm other studies showing that while European labor markets become more regulated, the American market has become increasingly flexible, unstable, and risky for employees. In Germany, we do not find evidence of an effect of the Hartz reforms of the beginning of the millennium, reducing long-term unemployment replacement rates to the level of basic income support (Sozialhilfe) and introducing stricter eligibility rules for welfare benefits and more employment flexibility (Minijobs, Ich-AGs, etc.), contrary to other studies that find more precariousness among the poor and lower earnings in jobs following unemployment after the reforms (Engbom, Detragiache, and Faezeh 2015). However, our definition of the periods may blur this effect. Larger data allowing more detailed timeframes may be better suited to investigate this.

We conclude our analysis by performing some robustness checks. First, it might be argued that the results of our analysis are sensitive to the different definition of equivalent income. Therefore, we adopt two alternative equivalence scales. We look at the old OECD equivalence scale, which assigns a value of 1 to the first household member, 0.7 to each additional adult and 0.5 to each child. We then use the modified OECD equivalence scale, which assigns a value of 1 to the household head, 0.5 to each additional adult member and 0.3 to each child. The results are reported in Figure 13-Figure 18 in the Appendix. Our main conclusions, that rank volatility profiles of these two countries did not differ substantially over the whole horizon considered and that poorer individuals in both countries experienced higher volatility than richer individuals, but that there is a diverging trend between Germany and the US, are not sensitive to the choice of the equivalence scale. However, using the OECD equivalence scale the results differ in that the lower quartile of the distribution in Germany was more mobile between 1983 and 1995 and that there is a greater and significant difference in the upper part of the income distribution during the period 1997-2009.

Second, it might be argued that the inclusion of pensioners that make up an even increasing share of the population may affect our estimations. Therefore, we perform two robustness checks: one on the sample made individuals older than 20, the other on the sample including individuals of all ages. The results of the former robustness check are reported in Figure 19-Figure 21 in the Appendix and confirm the U-shape characteristic of the profiles in both countries and that the poorer are the most volatile. Differently from our previous findings, instead, including this part of the sample determines a sharp difference between the volatility trend in Germany and US. Over the entire horizon considered, the US profile clearly dominates the German one, a dominance that is especially lead by the volatility experienced by the US population during 1997-2009. These results seem to indicate that the income insecurity among pensioners is a distinctive feature between both countries. Again, this is not surprising given the stable public pensions that cover a large part of the German elderly population compared to the US where old-age is more often associated with precariousness. The results of the latter are reported in Figure 22-Figure 24 in the Appendix. They, again, confirm the main features emphasized at the beginning of this section, with the only slight difference that the dominance of US over Germany in the second period is neater as well as the dominance of the first period over the second for the richest part of the population in Germany.

Additionally, we check for robustness by considering three periods instead of two to compute intertemporal rank and logitrank volatility. The results, reported in Figure 25-Figure 27 in the Appendix, are not affected by the choice of the number of periods used to compute rank and logitrank volatility.

Last, the existing literature has shown that the household structure changed substantially over the observation window impacting volatility trends (Peichl, Pestel, and Schneider 2012). Thus, we proceed by decomposing each profile of volatility in order to disentangle the effect due to change in income (see Figure 28-Figure 30 in the appendix) from the effect due to change in needs (see Figure 31-Figure 33 in the appendix). The result of this decomposition shows the relevance of the role played by income variations in determining overall volatility. The U-shape feature of all volatility profiles analyzed before is entirely determined by changes in income, given needs constant. Because we observe the same individuals only for a 2-year period, the role of change in 
needs (as proxied by the change in the number of household components) is very limited and may therefore be neglected.

\subsection{Comparing Individual Income Rank Volatility with Individual Income Volatility}

In this section, we compare the logitrank-based approach with the log-income-based approach to evaluate volatility. ${ }^{10}$ The value of our framework stick out when comparing the volatility profiles obtained with the logitrank-based method and with the income-based volatility measure (hereafter referred to as income volatility). Figure 5 compares - similarly to Figure 2 - volatility in West Germany and the US over the entire study period (1983-2009). Figure 6 shows the volatility profiles for West Germany and the US during the first and second period, 1983-1995 and 1997-2009, comparable to Figure 3. Figure 7 shows the separate evolution of volatility in West Germany and the US over time, comparable to Figure 4.

The U-shape of the rank volatility profiles shown in Figure 2-Figure 4 also characterizes the income volatility profiles shown in Figure 5-Figure 7 and Figure 11, which are of a higher amplitude further away from the median. However, volatility profiles based on income may, in general, prove to be an inconvenient tool for conducting comparisons, because income volatility is trivially higher in more unequal countries. In fact, apart from the U-shape of the profiles, patterns of income volatility clearly differ in relation to several features from the patterns obtained for logitrank volatility. For instance, income volatility is observed to be consistently lower than logitrank volatility, independently of the country or the period considered. By contrast, the gap between the profiles of the two countries shows a considerable increase when we focus on income volatility, both for the entire time span (1983-2009) and over the two shorter periods (1983-1995 and 1997-2009). The wider gap between Germany and US obtained using income volatility, in contrast to that obtained using logitrank volatility, reflects the higher level of inequality in the US compared to Germany (see Table 3). This can be explained as the impact of inequality on the measurement of income volatility as opposed to the neutrality of logitrank volatility in relation to inequality. It is also interesting to note that income volatility in the US consistently outplay income volatility in Germany during the first period. As we previously observed, logitrank volatility during this same period appeared, conversely, to be higher in Germany than in the US (Figure 3), with the exception of the lowest section of the distribution, that is, the section for which the gap between income volatility in Germany and the US appeared to be higher.

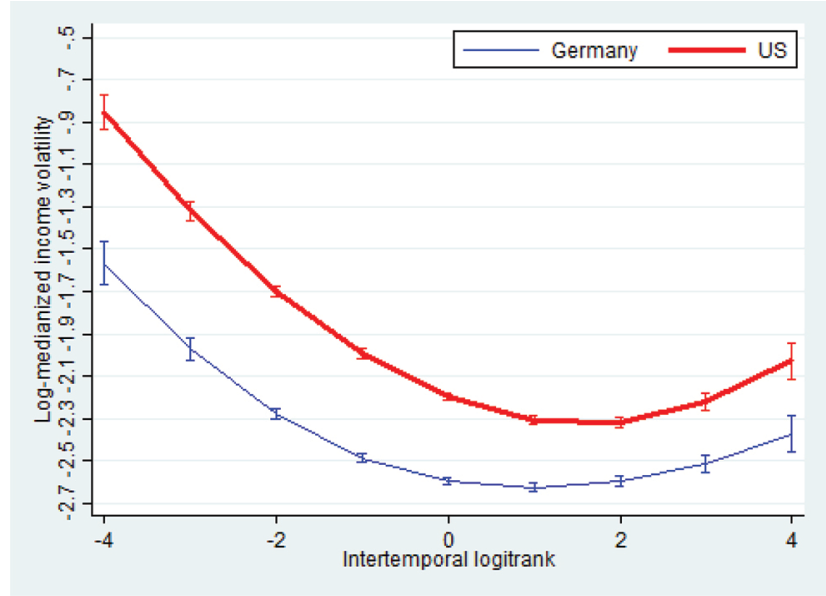

Figure 5: Log-medianized income volatility profiles in Germany and the US, 1983-2009.

Notes: Volatility including $95 \%$ convidence intervals depicted on the y-axis is estimated using eq. (6), but the log of the log-medianized income volatility is used as the dependent variable. Intertemporal logitrank refers to eq. (4). For the conversion between logitranks and percentile ranks see Table 1.

Source: Authors' computations based on the CNEF. 

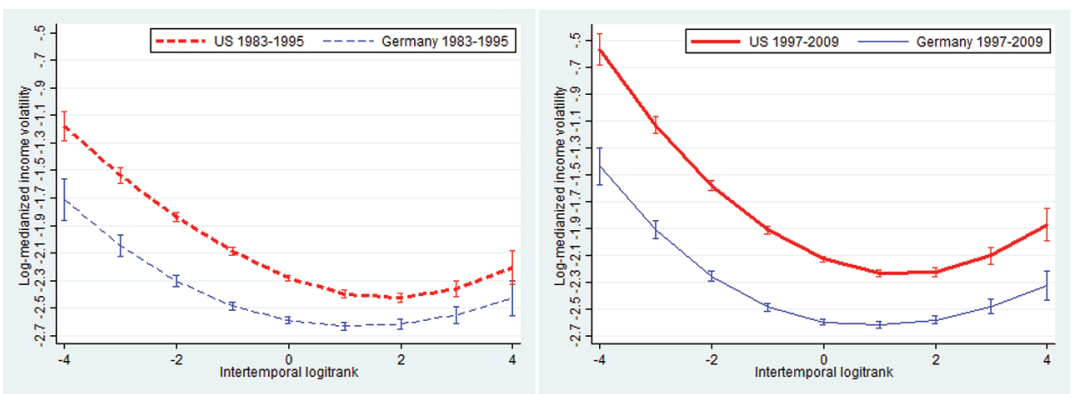

Figure 6: Log-medianized income volatility in 1983-1995 (left) and 1997-2009 (right): Germany versus the US.

Notes: Volatility including 95\% convidence intervals depicted on the y-axis is estimated using eq. (6), but the log of the log-medianized income volatility is used as the dependent variable. Intertemporal logitrank refers to eq. (4). For the conversion between logitranks and percentile ranks see Table 1. Source: Authors' computations based on the CNEF.
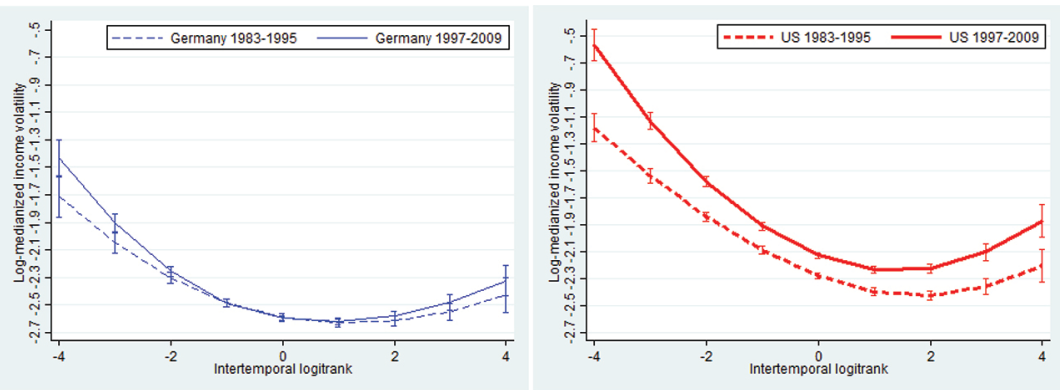

Figure 7: Log-medianized income volatility in Germany (left) and the US (right): 1983-1995 versus 1997-2009. Notes: Volatility including 95\% convidence intervals depicted on the y-axis is estimated using eq. (6). Intertemporal logitrank refers to eq. (4). For the conversion between logitranks and percentile ranks see Table 1.

Moreover, it should be noted that the time trend of the volatility profile for each country changes with a focus on income rather than on the income position measured by the logitrank. Again, this difference reflects the sensitivity of income-based measures of volatility to inequality in contrast to the neutrality that characterizes logitrank-based measures of volatility. This is particularly evident in the US case. Figure 4 (the panel on the left) displaying logitrank volatility in Germany indicates that a decline in volatility was experienced in the middle of the distribution. By contrast, Figure 7 (the panel on the left) suggests that volatility measured on the basis of incomes has remained quite stable over time, especially for the middle section of the distribution. As for the US, Figure 7 (panel on the right) is consistent with Figure 4 (panel on the right) only for the lower part of the distribution, where the second period was the most volatile. However, the difference between the first and second periods is noticeably greater in the case of income volatility than it is in the case of logitrank volatility (Figure 4, panel on the right). Divergent features related to the use of income volatility as opposed to logitrank volatility can once again be attributed to the sensitivity of income-based measures of volatility to differences in the stretching out of the distribution in the two countries, evidenced by the differential increases in their Gini coefficients (see Table 3 in the Appendix). The stability of the German income volatility profile over time, in contrast to the dramatic increase observed in the US profile, is mostly attributable to differences in the variation of the Gini coefficients in these countries: the increase of this index in the US was almost double that of its increase in Germany. As previously discussed, our methodology, based on logitrank, enables an assessment of volatility net of the changes generated by variations in income inequality.

\section{Conclusions}

Much research has discussed the hypothesis of increasing short-term unpredictability of income in view of the economic transformations and its institutional responses over the last decades (Moffitt and Zhang 2018; Hardy and Ziliak 2013; Bania and Leete 2009; Comin, Groshen, and Rabin 2009; Dahl, DeLeire, and Schwabish 2011; Dyan, Elmendorf, and Sichel 2012; Gottschalk and Moffitt 2002, 2009; Shin and Solon 2011). However, they neglect the impact of inequality on the measures of volatility used in cross-country comparisons. This paper addresses this issue by providing an innovative methodology based on logitranks of income that estimates volatility net of inequality trends. This strategy has moreover allowed us to better capture movements occurring at the tails of the distribution. Our framework endorses the view that income rank volatility provides 
additional information that would usefully complement the rooted consensus among scientists on the extent of income instability. Although there is an extensive literature across different disciplines that emphasize the significance of individuals' relative positions in the income distribution, volatility based on rank has not yet been explored. Eventually, we have used profiles of individual income rank volatility to better understand differences in volatility across the different parts of the distribution.

Applying our framework to West Germany and the US, we have demonstrated that, the rank volatility profiles of these two countries did not differ substantially between 1983 and 2009 and those poorer individuals in both countries experienced higher volatility than richer individuals. This volatility gap appears to be, however, higher in the US than in West Germany. Lower income classes in the US experienced increasing volatility over time. Conversely, West Germany middle class households became relatively more stable with respect to their income rank. In particular, we have demonstrated that, differently from the traditional approach that measures volatility in income, through our approach based on the rank as the main variable to analyze volatility, the gap between Germany and US narrows. This is due to the elimination of the marginal income distribution's impact that makes it possible to compare volatility levels and trends across countries regardless of their level of inequality.

Economic as well as institutional conditions are likely reasons behind the diverging income rank volatility profiles of West Germany and the US. Rodrik (1998), among others, claims that globalization, deregulation and technological change have increased competitive pressures and risks for employees, leading to growing income uncertainty for individuals. The task of disentangling the precise determinants of these trends is complicated since income - contrary to earnings - is a measure consisting of several components, whose volatility may reinforce or each other cancel out. Although this task is beyond the scope of this paper, our findings are in line with those of other studies. In particular, increasing income rank volatility in the US coincides with the end of the Fordist employment era and the trend towards increasing work incentives and labor market flexibility. The reduction of welfare and job security impacted particularly the hyperflexible, low-wage income group. Labor market flexibility coupled with institutional retrenchment, such as the Hartz reforms in the first half of the 2000s in Germany, seem also to have led to an increased exposure to macro-economic shocks in this group. The concentration of increased volatility in the lower-middle classes should raise concerns about whether consumption and well-being in this population has been adversely affected, in particular given their liquidity constraints and imperfect risk insurance. Conversely, the better-off, upper middle class has been better able to defend its economic status, partly through adjustments in labor intensity (see Gershuny 2000).

Institutional arrangements such as labor market policies and the welfare state can either buffer or reinforce the adverse effects of economic conditions, but seem to show the biggest effect at the lower end of the distribution (Hill et al. 2017; Sologon and O'Donoghue 2014; Rohde, Tang, and Rao 2014; Bartels and Bönke 2013). The tax system and income replacement rates, for instance, differ vastly between Germany and the US impacting volatility levels differently in both countries (Chen 2009). Germany is characterized by a more progressive tax system leading to greater redistribution than in the US. In Germany, the unemployment net replacement rate amounted for a one-earner married couple in the initial phase $73 \%$ in Germany compared to $49 \%$ in the US in 2014 (OECD 2016a). Employment protection is much lower in the US, especially for temporary workers (1.2 for permanent workers and 0.3 for temporary workers), than in Germany (3.0 and 1.8, respectively) (OECD 2016b). Over the last decades, the German labor market has experienced profound structural transformations as well as a strong deregulation and deunionization (Bönke, Giesecke, and Lüthen 2015). The German system seems to be, despite its reforms in the last one and a half decade downsizing benefits (Hartz reforms), better suited for smoothing income shocks, showing less pronounced impacts of neoliberalization and risk-shifting towards the market and the family than in the US, where social security seems to be less effective in smoothing income instability among the bottom quintile since 1980 (Bartels and Bönke 2013; Hardy 2017).

Last, it deserves to be noted that, the German reunification did, contrary to our expectations, not increase volatility in West Germany through an altered earnings structure. Rather, this major political transformation seems to have led to stability, as witnessed in the West German upper-middle class. Volatility trends in East Germany, however, might be very different from those in West Germany.

This work can be extended in a number of other directions. From a methodological perspective, this framework can be applied to an analysis of structural versus exchange mobility. Empirically, a potential area of application of our work would be the European context, in which countries exhibit very different systems of labor and income regulations. With more recent data future research could investigate the effects of the financial crisis on the U-shape of the income rank volatility profiles and the role of national specificities in this process to understand whether and how the austerity policies have affected individual instability. 


\section{Acknowledgment}

We thank the editor and two anonymous referees for their valuable suggestions and comments. We are also grateful to Peter Gottschalk (Boston College) for his fruitful comments on an early version of the paper.

\section{Funding}

This work was supported by Fonds National de la Recherche Luxembourg, Funder Id: 10.13039/501100001866, Grant Number: FNR/P11/05 Prosocial

\section{Appendix}

Table 2: Estimated coefficients of the logitrank volatility profiles.

\begin{tabular}{|c|c|c|c|c|c|c|}
\hline & \multicolumn{2}{|c|}{ Figure 2: Overall (1983-2009) } & \multicolumn{2}{|c|}{$\begin{array}{l}\text { Figure 3: First period } \\
(1983-1995)\end{array}$} & \multicolumn{2}{|c|}{$\begin{array}{l}\text { Figure 3: Second } \\
\text { period (1997-2009) }\end{array}$} \\
\hline & US & Germany & US & Germany & US & Germany \\
\hline$\beta_{1}$ & -0.0137 & -0.0171 & 0.0168 & -0.0095 & -0.0377 & -0.0238 \\
\hline (s.e.) & $(0.0131)$ & $(0.0147)$ & $(0.0179)$ & $(0.0201)$ & $(0.0173)$ & $(0.0191)$ \\
\hline \multirow[t]{2}{*}{ [c.i.] } & {$[-0.0393$} & {$[-0.0460$} & {$[-0.0182$} & {$[-0.0489$} & {$[-0.0716$} & {$[-0.0611$,} \\
\hline & $0.0120]$ & 0.0119] & $0.0518]$ & $0.0299]$ & $-0.0037]$ & $0.0136]$ \\
\hline$\beta_{2}$ & 0.0494 & 0.0390 & 0.0538 & 0.0345 & 0.0470 & 0.0440 \\
\hline (s.e.) & $(0.0048)$ & $(0.0056)$ & $(0.0065)$ & $(0.0083)$ & $(0.0065)$ & $(0.0074)$ \\
\hline \multirow[t]{2}{*}{ [c.i.] } & {$[0.0400$,} & {$[0.0280$,} & {$[0.0410$,} & {$[0.0182$} & {$[0.0342$,} & {$[0.0293$} \\
\hline & $0.0588]$ & 0.0500] & $0.0665]$ & 0.0507] & $0.0598]$ & $0.0585]$ \\
\hline$\beta_{3}$ & 0.0205 & 0.0247 & 0.0092 & 0.0191 & 0.0300 & 0.0301 \\
\hline (s.e.) & $(0.0059)$ & $(0.0062)$ & $(0.0084)$ & $(0.0083)$ & $(0.0073)$ & $(0.0083)$ \\
\hline \multirow[t]{2}{*}{ [c.i.] } & {$[0.0089$,} & {$[0.0125$,} & {$[-0.0073$,} & {$[0.0029$,} & {$[0.0156$,} & {$[0.0138$,} \\
\hline & $0.0320]$ & 0.0368 ] & $0.0257]$ & $0.0353]$ & $0.0444]$ & $0.0463]$ \\
\hline$\beta_{0}$ & -1.2358 & -1.2676 & -1.2582 & -1.2307 & -1.2179 & -1.3050 \\
\hline (s.e.) & $(0.0098)$ & $(0.0101)$ & $(0.0131)$ & $(0.0141)$ & $(0.0130)$ & $(0.0137)$ \\
\hline \multirow[t]{2}{*}{ [c.i.] } & {$[-1.2551$,} & {$[-1.2874$,} & {$[-1.2840$} & {$[-1.2584$,} & {$[-1.2433$} & {$[-1.3318$,} \\
\hline & $-1.2166]$ & $-1.2477]$ & $-1.2325]$ & $-1.2030]$ & $-1.1925]$ & $-1.2781]$ \\
\hline
\end{tabular}

Note: $95 \%$ confidence intervals displayed.

Source: Authors' computations based on the CNEF.

Table 3: Descriptive statistics.

\begin{tabular}{|c|c|c|c|c|c|c|}
\hline \multirow[t]{2}{*}{ Years (first period) } & \multicolumn{2}{|c|}{ Gini coefficients } & \multicolumn{2}{|c|}{ Mean income } & \multicolumn{2}{|c|}{ Median income } \\
\hline & Germany & US & Germany & US & Germany & US \\
\hline 1983 & 0.248 & 0.305 & $19,066.63$ & $26,804.40$ & $17,560.96$ & $24,140.51$ \\
\hline 1985 & 0.244 & 0.324 & $19,375.64$ & $29,019.95$ & $18,038.77$ & $25,844.02$ \\
\hline 1987 & 0.241 & 0.325 & $20,097.05$ & $30,151.11$ & $18,581.25$ & $26,869.36$ \\
\hline 1989 & 0.247 & 0.355 & $21,266.93$ & $33,665.32$ & $19,527.33$ & $28,447.31$ \\
\hline 1991 & 0.251 & 0.343 & $22,815.52$ & $32,989.39$ & $20,936.70$ & $28,469.57$ \\
\hline 1993 & 0.256 & 0.353 & $22,737.76$ & $33,937.90$ & $20,683.63$ & $29,107.44$ \\
\hline 1995 & 0.264 & 0.366 & $21,904.26$ & $33,057.05$ & $19,780.96$ & $27,882.62$ \\
\hline Average first period & 0.250 & 0.339 & $21,037.68$ & $31,375.01$ & $19,301,37$ & $27,251.55$ \\
\hline \multirow[t]{2}{*}{ Years (second period) } & \multicolumn{2}{|c|}{ Gini coefficients } & \multicolumn{2}{|c|}{ Mean income } & \multicolumn{2}{|c|}{ Median income } \\
\hline & Germany & US & Germany & US & Germany & US \\
\hline 1997 & 0.256 & 0.361 & $21,911.51$ & $36,451.36$ & $19,639.17$ & $31,061.61$ \\
\hline 1999 & 0.256 & 0.392 & $23,222.13$ & $38,179.70$ & $20,924.61$ & $30,797.36$ \\
\hline 2001 & 0.268 & 0.374 & $23,285.36$ & $41,773.56$ & $20,796.84$ & $34,160.58$ \\
\hline
\end{tabular}




\begin{tabular}{lllllll}
2003 & 0.251 & 0.370 & $22,411.41$ & $40,494.11$ & $20,851.26$ & $33,912.66$ \\
2005 & 0.276 & 0.409 & $22,984.75$ & $43,102.00$ & $20,489.17$ & $34,328.96$ \\
2007 & 0.282 & 0.429 & $24,193.21$ & $42,477.54$ & $21,583.15$ & $32,746.29$ \\
2009 & 0.278 & 0.409 & $24,725.93$ & $42,273.13$ & $22,109.36$ & $33,507.18$ \\
Average second period & 0.267 & 0.392 & $23,247,76$ & $40,678.77$ & $20,913,37$ & $32,930.66$ \\
\hline
\end{tabular}

Note: Mean and median income are expressed in 2010 Euro for Germany and in 2010 US Dollar for the US. Source: Authors' computations based on CNEF.

Table 4: Point estimates and confidence intervals of volatility profiles in Germany and the US (Figure 10).

\begin{tabular}{lllll}
\hline Logitrank & Germany & Germany & US & US \\
& $\mathbf{1 9 8 3 - 1 9 9 5}$ & $\mathbf{1 9 9 7 - 2 0 0 9}$ & $\mathbf{1 9 8 3 - 1 9 9 5}$ & $\mathbf{1 9 9 7 - 2 0 0 9}$ \\
\hline-4 & -0.641 & -0.507 & -0.465 & -0.315 \\
(c.i.) & $(-0.782,-0.500)$ & $(-0.640,-0.373)$ & $(-0.568,-0.362)$ & $(-0.421,-0.210)$ \\
-3 & -0.892 & -0.838 & -0.825 & -0.682 \\
(c.i.) & $(-0.961,-0.823)$ & $(-0.908,-0.769)$ & $(-0.877,-0.773)$ & $(-0.735,-0.629)$ \\
-2 & -1.074 & -1.082 & -1.077 & -0.955 \\
(c.i.) & $(-1.114,-1.034)$ & $(-1.123,-1.040)$ & $(-1.112,-1.042)$ & $(-0.990,-0.919)$ \\
-1 & -1.187 & -1.237 & -1.221 & -1.133 \\
(c.i.) & $(-1.222,-1.151)$ & $(-1.271,-1.204)$ & $(-1.252,-1.191)$ & $(-1.165,-1.102)$ \\
0 & -1.231 & -1.305 & -1.258 & -1.218 \\
(c.i.) & $(-1.258,-1.203)$ & $(-1.332,-1.278)$ & $(-1.284,-1.233)$ & $(-1.243,-1.192)$ \\
1 & -1.221 & -1.299 & -1.232 & -1.226 \\
(c.i.) & $(-1.258,-1.184)$ & $(-1.335,-1.262)$ & $(-1.268,-1.197)$ & $(-1.259,-1.192)$ \\
2 & -1.173 & -1.232 & -1.188 & -1.173 \\
(c.i.) & $(-1.218,-1.128)$ & $(-1.274,-1.191)$ & $(-1.233,-1.143)$ & $(-1.214,-1.132)$ \\
3 & -1.087 & -1.106 & -1.125 & -1.061 \\
(c.i.) & $(-1.163,-1.011)$ & $(-1.178,-1.033)$ & $(-1.211,-1.040)$ & $(-1.132,-0.990)$ \\
4 & -0.962 & -0.919 & -1.044 & -0.888 \\
(c.i.) & $(-1.111,-0.814)$ & $(-1.066,-0.772)$ & $(-1.211,-0.877)$ & $(-1.025,-0.751)$ \\
\hline
\end{tabular}

Note: $95 \%$ confidence intervals displayed.

Source: Authors' computations based on CNEF.

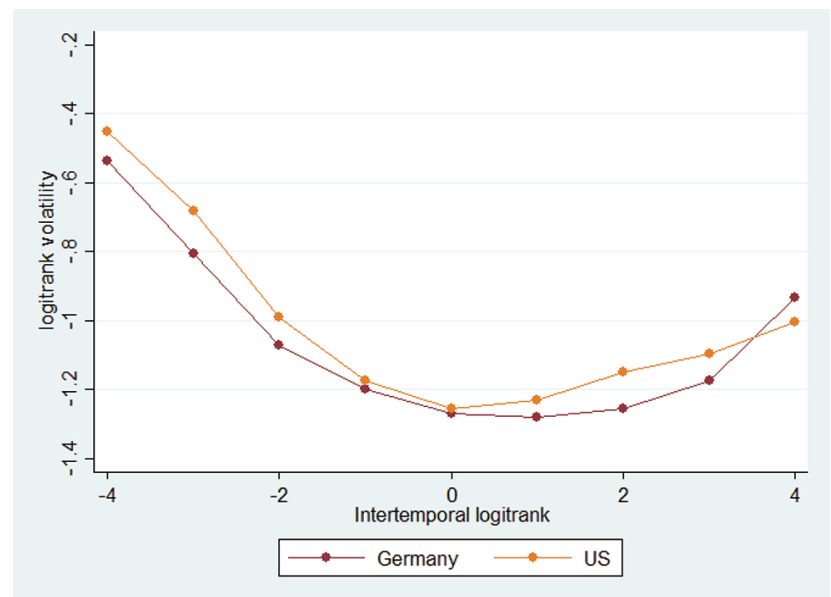

Figure 8: Observed average 2-year volatility in Germany and US, 1983-2009.

Notes: Volatility on the y-axis refers to the log of eq. (5). Intertemporal logitrank refers to eq. (4). Table 1 shows the conversion between logitranks and percentile ranks. C.I. denotes the confidence intervals.

Source: Authors' computations based on the CNEF. 


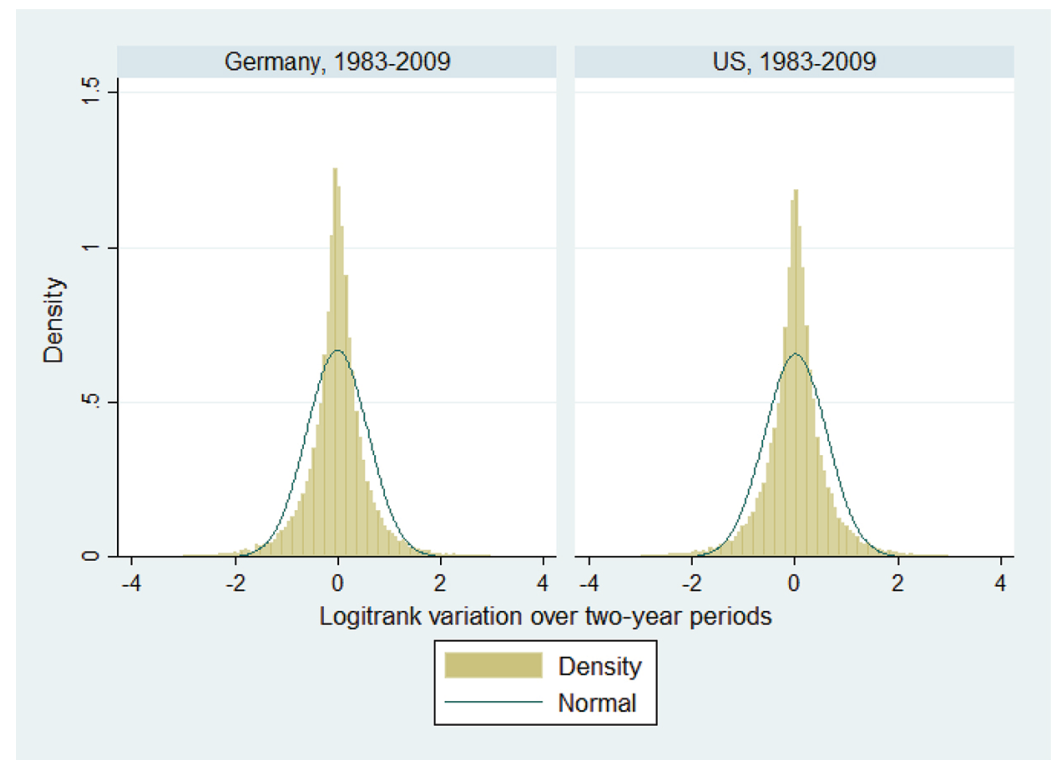

Figure 9: Logitrank variations during the two periods in Germany and the US, 1983-2009. Source: Authors' computations based on CNEF.

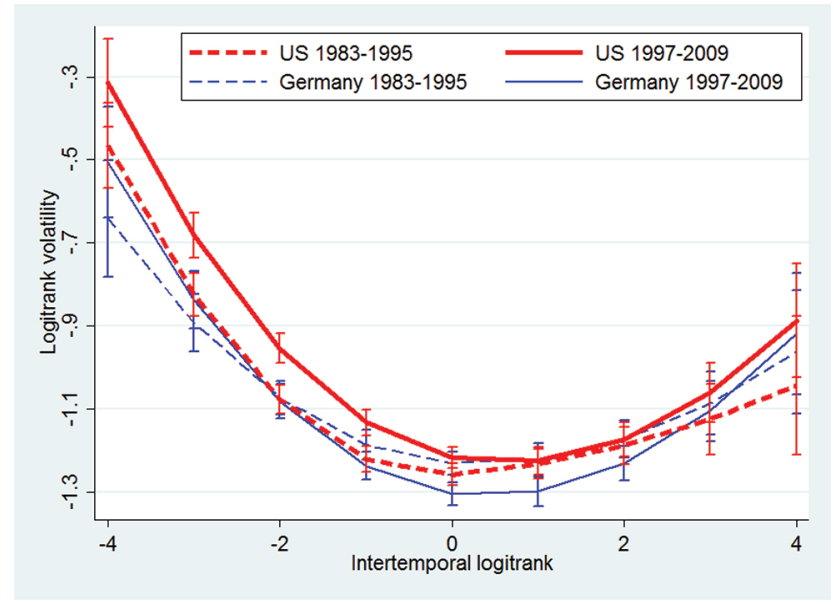

Figure 10: Logitrank volatility profiles in Germany and the US, 1983-1995 and 1997-2009.

Notes: Volatility on the y-axis is estimated using eq. (6). Intertemporal logitrank refers to eq. (4). See Table 1 for the conversion between logitranks and percentile ranks. C.I. denotes the confidence intervals. See Table 4 for precise point estimates and confidence intervals.

Source: Authors' computations based on the CNEF.

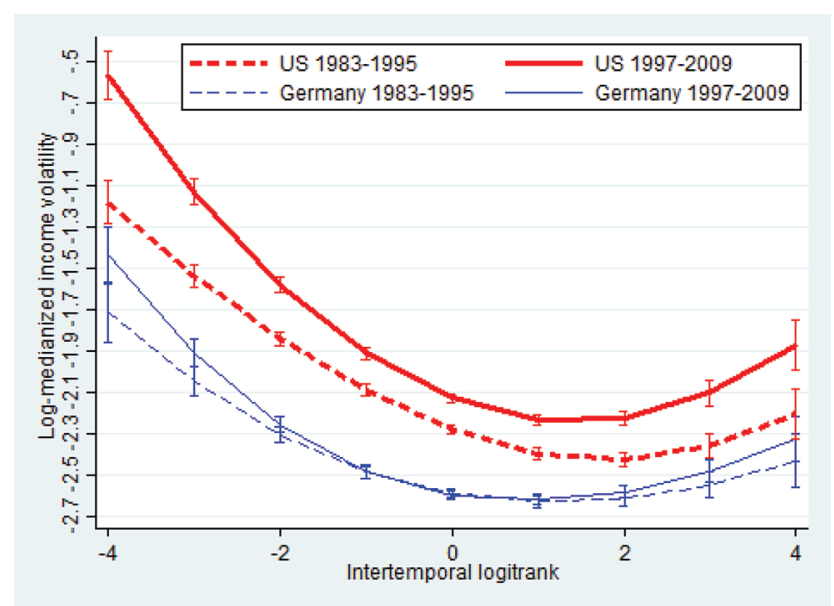


Figure 11: A comparison of log-medianized income volatility in Germany and the US during the periods $1983-1995$ and 1997-2009.

Notes: Volatility on the y-axis is estimated using eq. (6), but the log of the medianized-income volatility is used in this case as the dependent variable. Intertemporal logitrank refers to eq. (4), for the conversion between logitranks and percentile ranks see Table 1. C.I. denotes the confidence intervals.

Source: Authors' computations based on the CNEF.

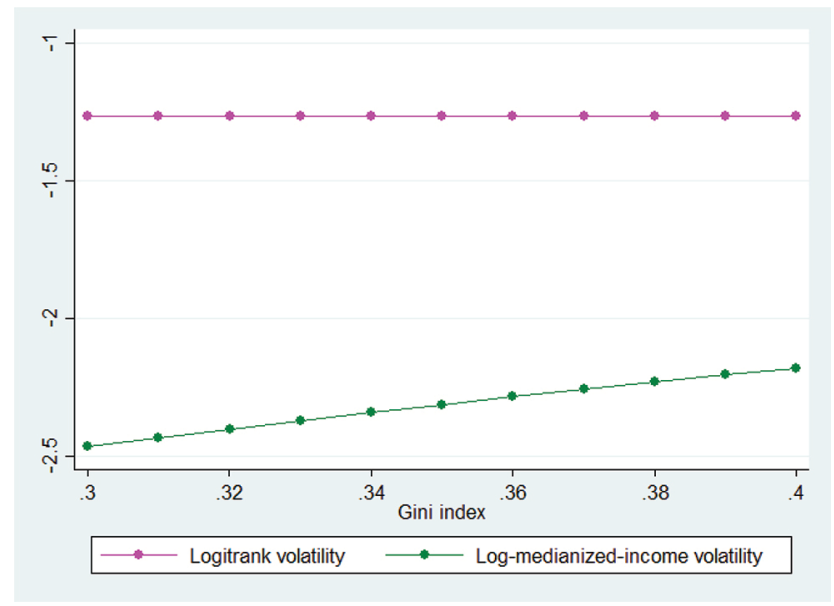

Figure 12: A comparison of logitrank and log-income volatility with Increasing Inequality. Note: Logitrank volatility and log-medianized income volatility refer to individuals whose logitrank is 0 , that is, those situated at the median of the distribution. Source: Authors' simulation based on CNEF (US).

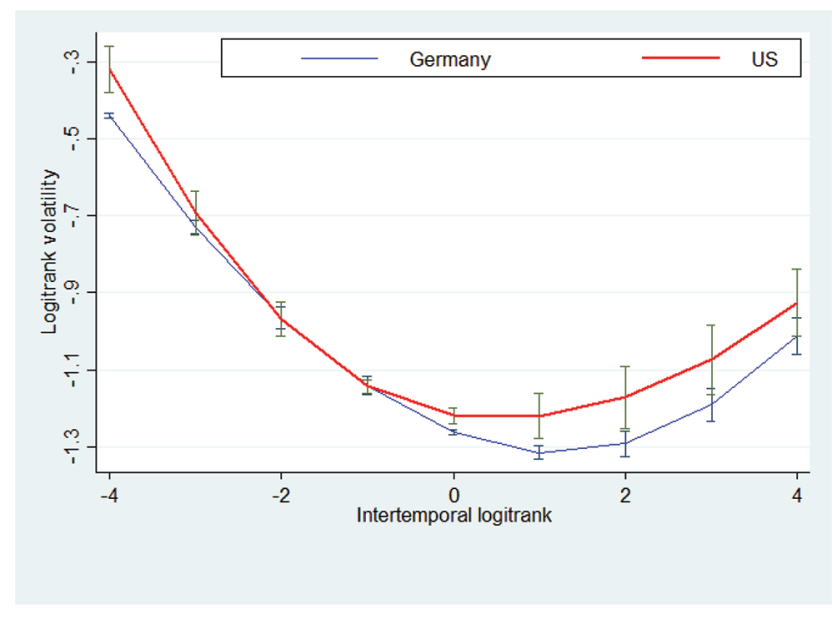

Figure 13: Logitrank volatility profiles in West Germany and the US, 1983-2009 - using OECD equivalence scale. Source: Authors' computations based on the CNEF.
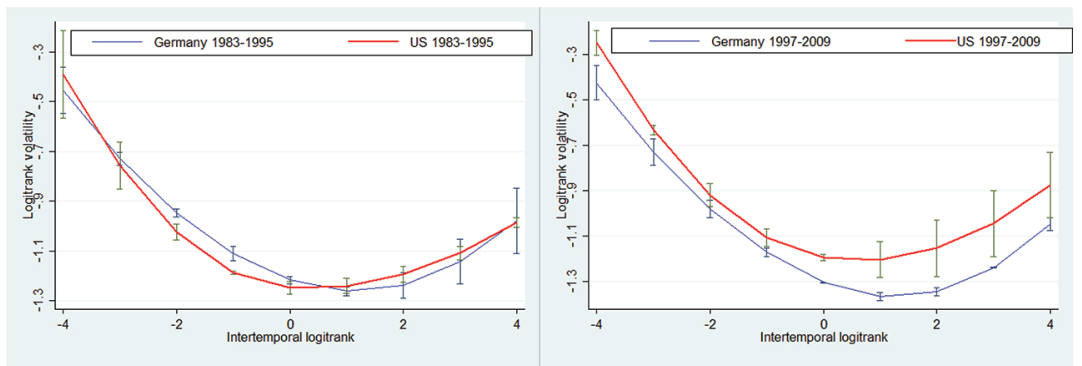

Figure 14: Logitrank volatility profiles in 1983-1995 (left) and 1997-2009 (right): Germany versus the US - using OECD equivalence scale.

Source: Authors' computations based on the CNEF. 

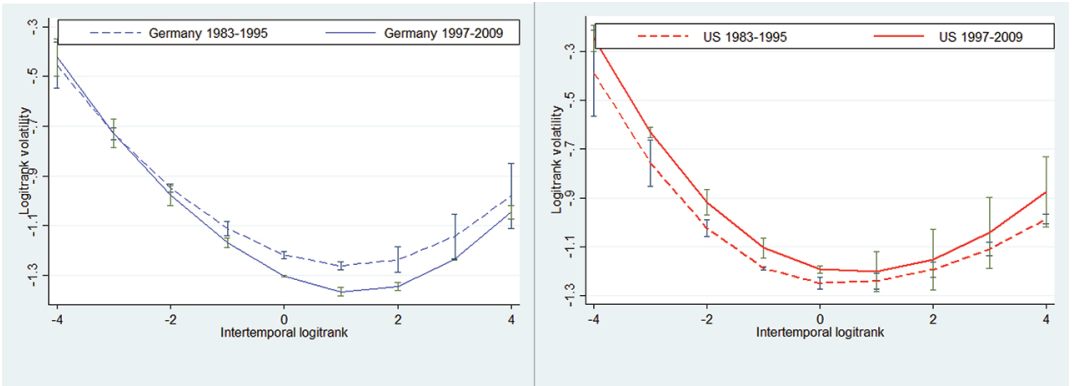

Figure 15: Logitrank volatility profiles in Germany (left) and the US (right), 1983-1995 versus 1997-2009 - using OECD equivalence scale. Source: Authors' computations based on the CNEF.

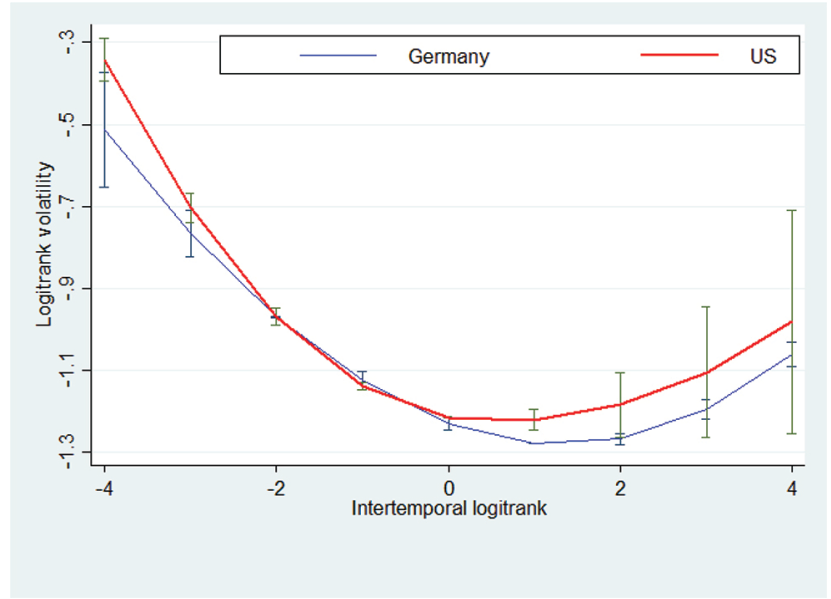

Figure 16: Logitrank volatility profiles in West Germany and the US, 1983-2009 - using modified OECD equivalence scale.

Source: Authors' computations based on the CNEF.
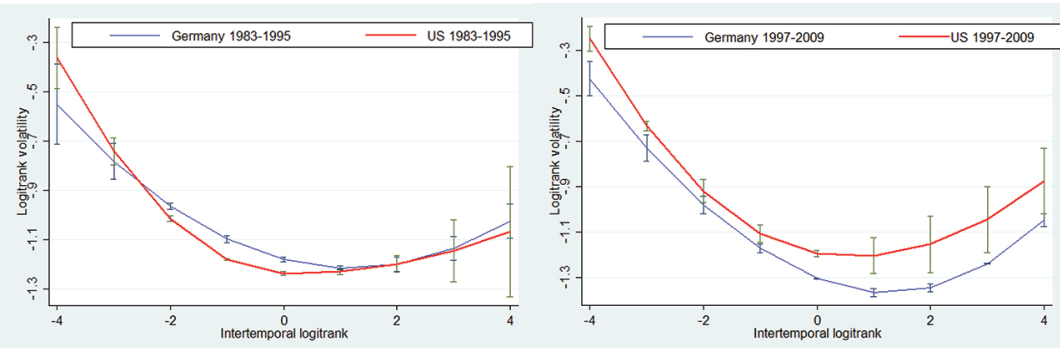

Figure 17: Logitrank volatility profiles in 1983-1995 (left) and 1997-2009 (right): Germany versus the US - using modified OECD equivalence scale.

Source: Authors' computations based on the CNEF.
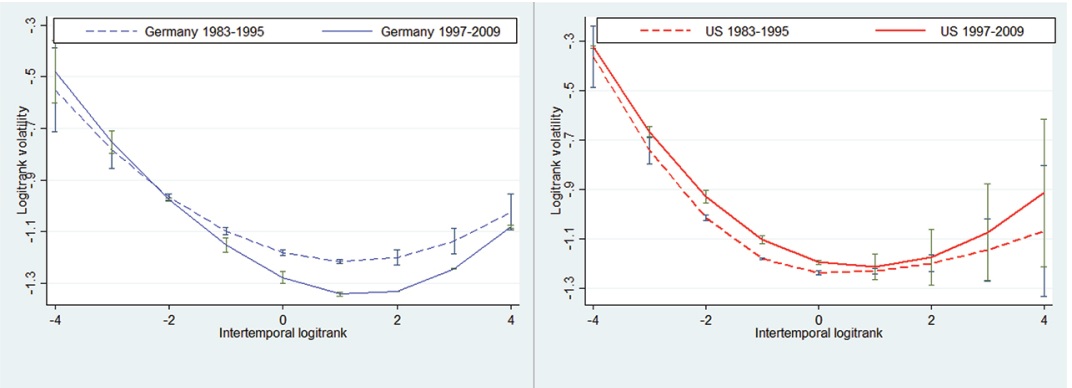

Figure 18: Logitrank volatility profiles in Germany (left) and the US (right), 1983-1995 versus 1997-2009 - using modified OECD equivalence scale.

Source: Authors' computations based on the CNEF. 


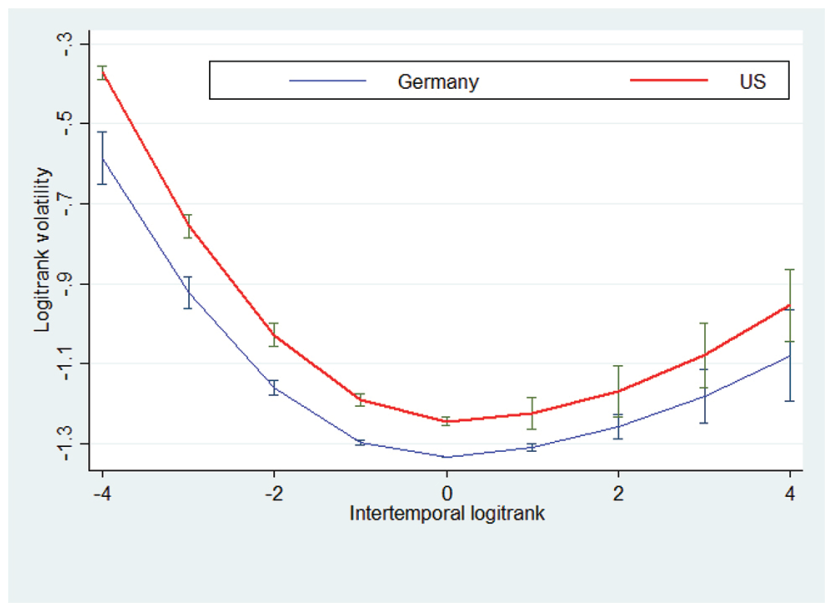

Figure 19: Logitrank volatility profiles in West Germany and the US, 1983-2009 - individuals older than 20. Source: Authors' computations based on the CNEF.
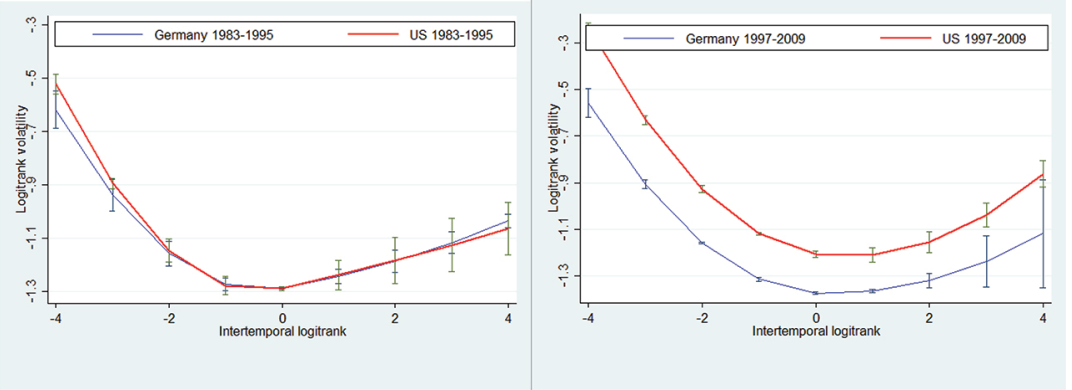

Figure 20: Logitrank volatility profiles in 1983-1995 (left) and 1997-2009 (right): Germany versus the US - individuals older than 20.

Source: Authors' computations based on the CNEF.
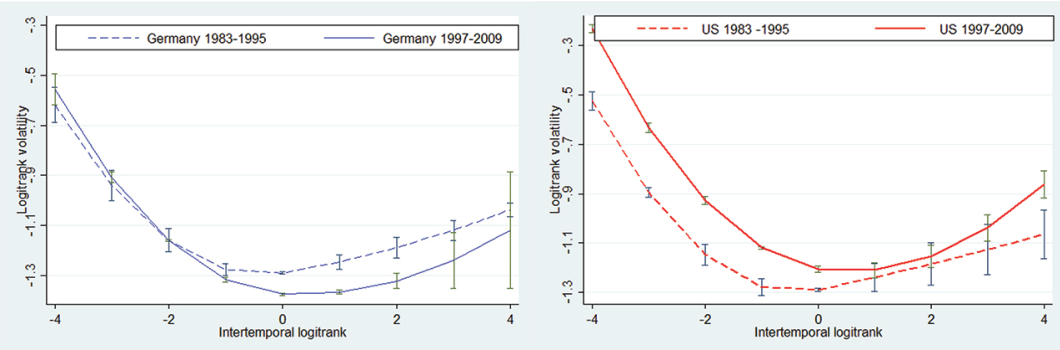

Figure 21: Logitrank volatility profiles in Germany (left) and the US (right), 1983-1995 versus 1997-2009 - individuals older than 20.

Source: Authors' computations based on the CNEF.

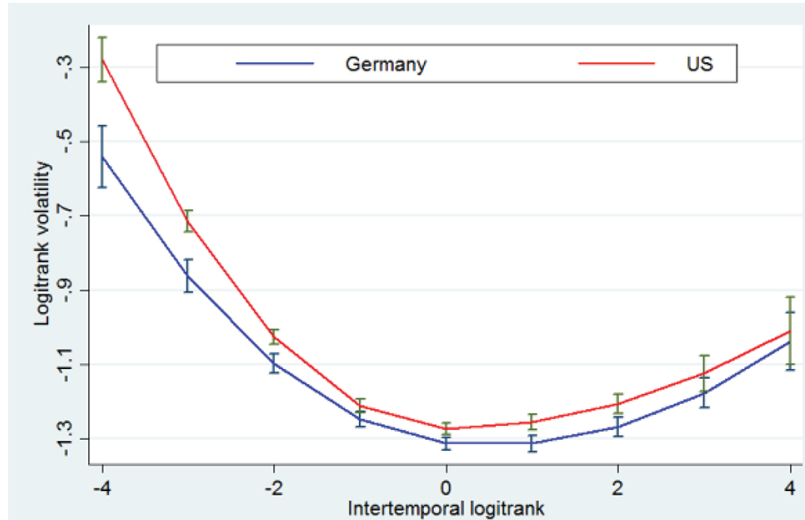


Figure 22: Logitrank volatility profiles in West Germany and the US, 1983-2009 - individuals of all ages. Source: Authors' computations based on the CNEF.
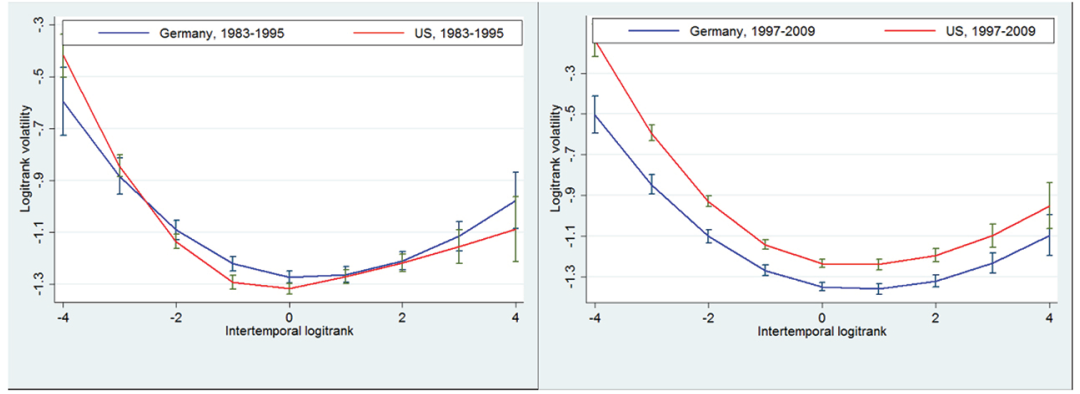

Figure 23: Logitrank volatility profiles in 1983-1995 (left) and 1997-2009 (right): Germany versus the US - individuals of all ages.

Source: Authors' computations based on the CNEF.
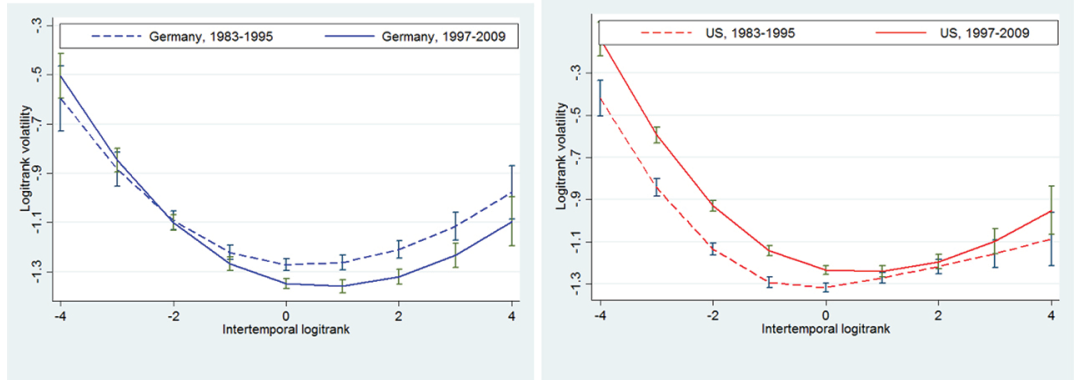

Figure 24: Logitrank volatility profiles in Germany (left) and the US (right), 1983-1995 versus 1997-2009 - individuals of all ages.

Source: Authors' computations based on the CNEF.

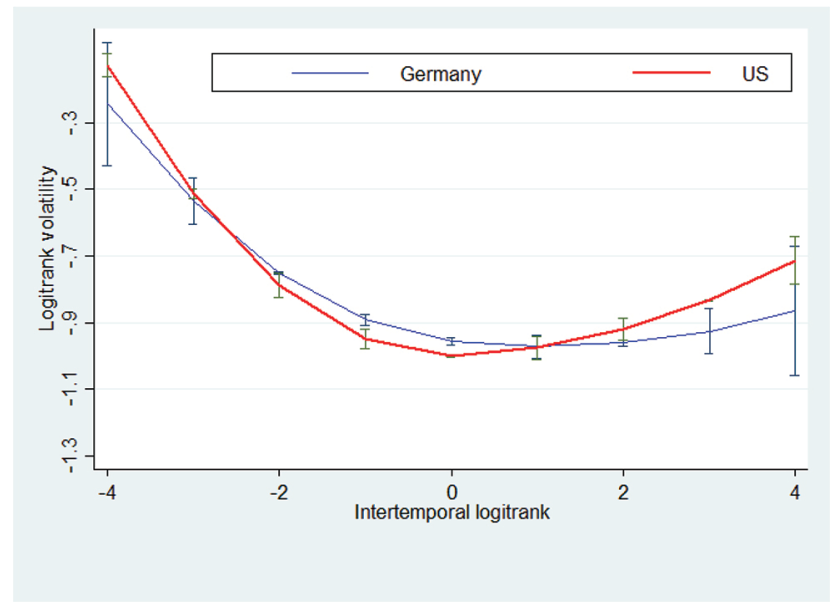

Figure 25: Logitrank volatility profiles in West Germany and the US, 1983-2009 - three-period volatility. Source: Authors' computations based on the CNEF.
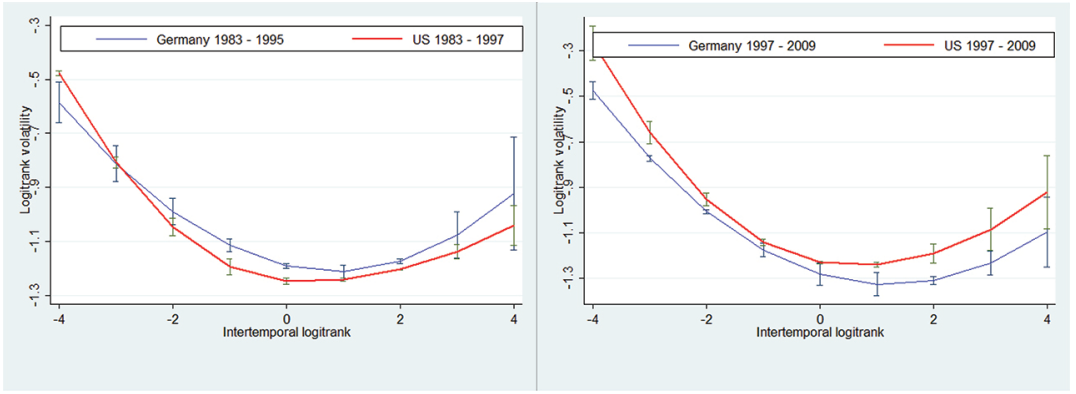

Figure 26: Logitrank volatility profiles in 1983-1995 (left) and 1997-2009 (right): Germany versus the US - three-period volatility.

Source: Authors' computations based on the CNEF. 

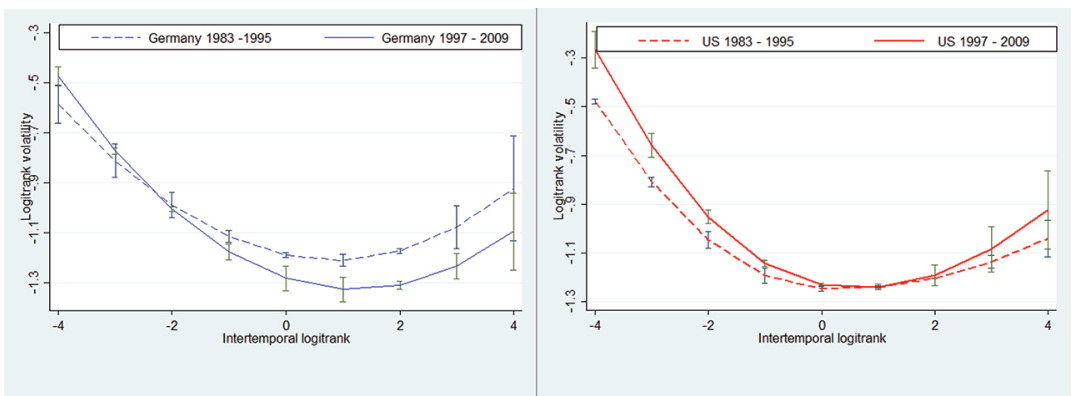

Figure 27: Logitrank volatility profiles in Germany (left) and the US (right), 1983-1995 versus 1997-2009 - three-period volatility.

Source: Authors' computations based on the CNEF.

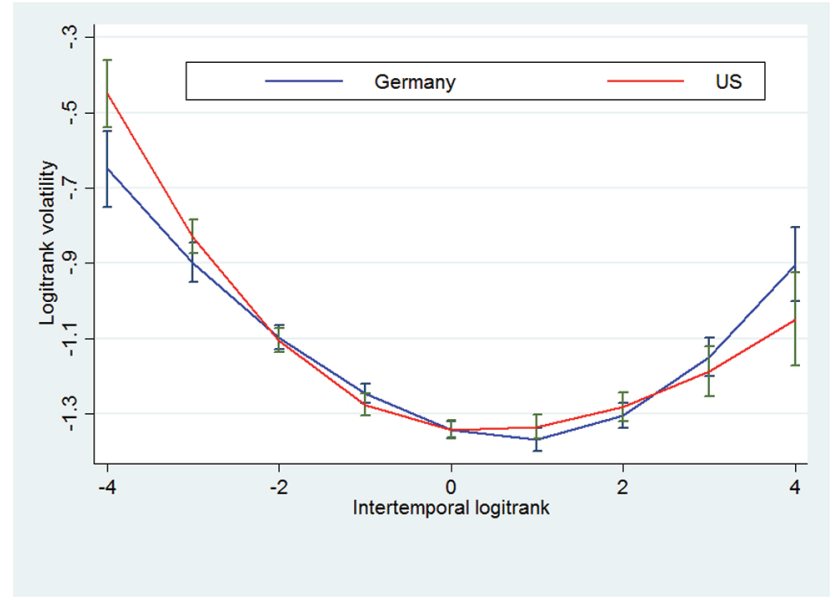

Figure 28: Logitrank volatility profiles in West Germany and the US, 1983-2009 - holding household composition constant.

Source: Authors' computations based on the CNEF.
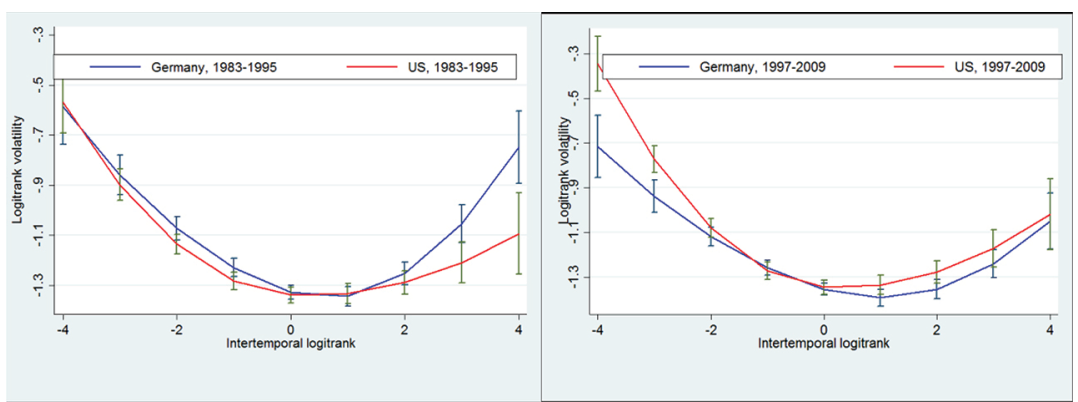

Figure 29: Logitrank volatility profiles in 1983-1995 (left) and 1997-2009 (right): Germany versus the US - holding household composition constant.

Source: Authors' computations based on the CNEF.

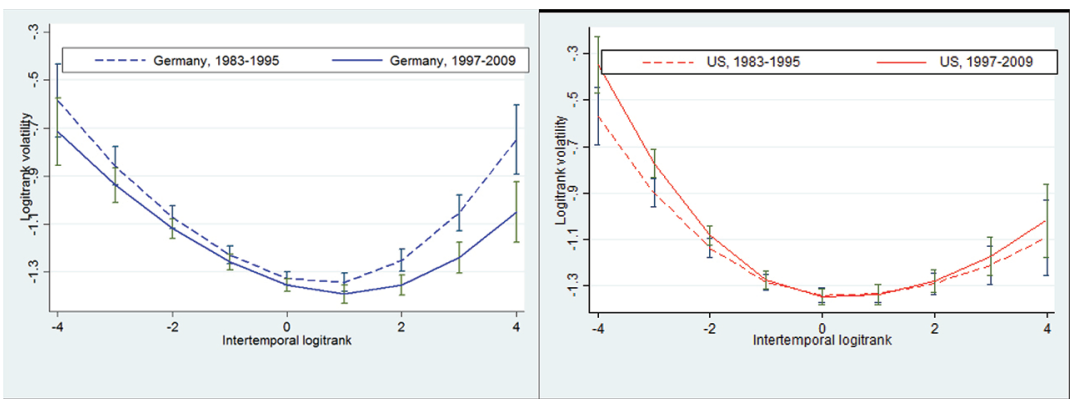

Figure 30: Logitrank volatility profiles in Germany (left) and the US (right), 1983-1995 versus 1997-2009 - holding household composition constant.

Source: Authors' computations based on the CNEF. 


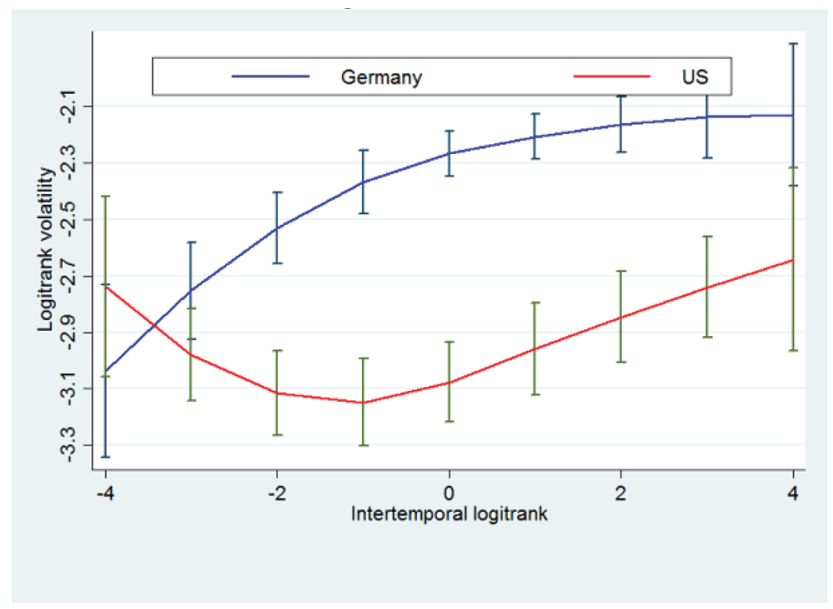

Figure 31: Logitrank volatility profiles in West Germany and the US, 1983-2009 - holding income constant. Source: Authors' computations based on the CNEF.
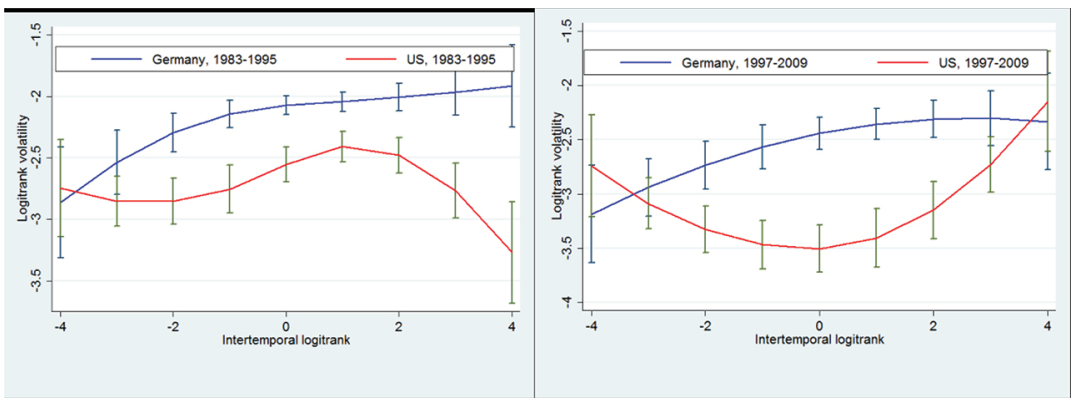

Figure 32: Logitrank volatility profiles in 1983-1995 (left) and 1997-2009 (right): Germany versus the US - holding income constant.

Source: Authors' computations based on the CNEF.
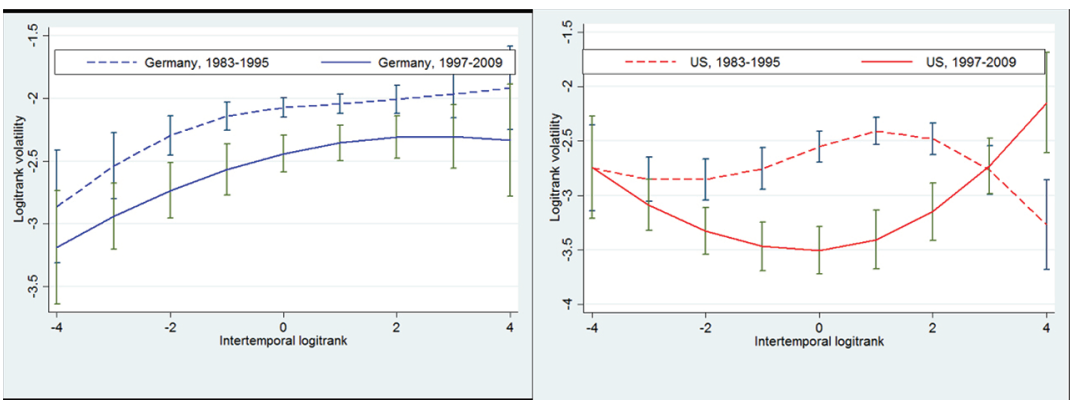

Figure 33: Logitrank volatility profiles in Germany (left) and the US (right), 1983-1995 versus 1997-2009 - holding income constant.

Source: Authors' computations based on the CNEF.

\section{Notes}

1 By "aggregate measure" we mean the use of a representative aggregate to express instability within a given society as opposed to the use of individual level data on instability.

2 See, inter alia, D'Agostino and Dardanoni (2009) for an alternative application of the rank-based approach in the context of mobility measurement.

3 The reader may notice that we use the word "structural" to refer to the individual volatility that results only from the changes in the marginal distribution of income, as distinct from the volatility generated by the change in the rank. It does not refer to the difference between exogenous and endogenous factors affecting individual volatility.

4 Note that the use of "heterogeneity" here does not refer to different sources of volatility, but rather to variations in volatility and volatility trends among different sections of the distribution.

5 In this paper, we use the term "exchange mobility" to refer to a change in the rank of individuals in the distribution over a given period of time.

6 See Jäntti and Jenkins (2015) on the relevance of focusing on rank rather than on income in the measurement of mobility.

7 The PSID changed in 1997 from annual to biannual survey. 
8 Non-random panel attrition is a potential challenge for longitudinal cross-national comparison. However, Frick et al. (2007) claim that "Because, in most panel surveys, attrition typically stabilizes after a few waves at quite low rates [...], attrition rates do not vary as much across the CNEF country samples." In particular, the two datasets we use here (PSID and SOEP) are among the existing datasets less affected by attrition. In addition, as we follow individuals only for a period of two years, attrition is unlikely to represent a major issue in our analysis.

9 Note that we use an individual based measure of volatility as opposed to an aggregate measure such as for instance the sample standard deviation of the distribution of individual changes in log income between that year and an earlier year.

10 In Figure 12 in the appendix, we first present a simulation assuming that the only change affecting income distribution is the variation in inequality over time. It confirms that while volatility based on the traditional approach (log-medianized income volatility) increases with an increase in inequality, logitrank volatility remains constant. This evidently follows from eq. (2). The STATA dofile for replicating the simulation is available as supplementary material.

\section{References}

Bania, N., and L. Leete. 2009. “Monthly Household Income Volatility in the U.S., 1991/92 Vs. 2002/03." Economics Bulletin 29 (3): $2100-12$.

Bar-Haim, E., L. Chauvel, J. Cornick, and A. Hartung, Anne (2018) “Closing or persisting gender wage gap? A cohort analysis of education and earnings in the US and Europe." LIS Working Paper Series, No. 737, http://www.lisdatacenter.org/wps/liswps/737.pdf.

Bar-Haim, E., L. Chauvel, L. and A. Hartung. 2019. “More necessary and less sufficient: an age-period-cohort approach to overeducation from a comparative perspective." Higher Education.10.1007/s10734-018-0353-z.

Bartels, C., and T. Bönke. 2013. “Can Households and Welfare States Mitigate Rising Earnings Instability?” Review of Income and Wealth 59 (2): $250-82$.

Bayaz-Ozturk, G., R.V. Burkhauser, and K.A. Couch. 2014. “Consolidating the Evidence on Income Mobility in the Western States of Cermany and the U.S. From 1984 to 2006 ." Economic Inquiry 52 (1): 431-43.

Bönke, T., M. Ciesecke, and H. Lüthen 2015. The Dynamics of Earnings in Cermany: Evidence from Social Security Records. Discussion Paper, DIW Berlin, No. 1514.

Chauvel, L. 2016. "Intensity and Shape of Inequalities: The ABC Method for the Analysis of Distributions." Review of Income and Wealth 62 (1): $52-68$.

Chen, W. 2009. “Cross-National Differences in Income Mobility: Evidence from Canada, the United States, Great Britain and Cermany." Review of Income and Wealth 55: 75-100.

Clark, A., N. Kristensen, and N. Westergard-Nielsen. 2009. “Economic Satisfaction and Income Rank in Small Neighbourhoods." Journal of the European Economic Association 7: 519-27.

Comin, D., E.L. Groshen, and B. Rabin. 2009. “Turbulent Firms, Turbulent Wages?” Journal of Monetary Economics 56 (1): 109-33.

D’Agostino, M., and V. Dardanoni. 2009. “The Measurement of Rank Mobility." Journal of Economic Theory 144 (4): 1783-803.

Dahl, M., T. DeLeire, and J. Schwabish. 2011. “Estimates of Year-to-Year Variability in Worker Earnings and in Household Incomes from Administrative, Survey, and Matched Data." Journal of Human Resources 46 (4): 750-74.

Daly, M., and R. Valletta. 2008. "Cross-National Trends in Earnings Instability and Earnings Inequality." Economics Letters 99: 215-19.

Dyan, K., D. Elmendorf and D. Sichel. 2012 (1) 18. “The Evolution of Household Income Volatility." The B.E. Journal of Economic Analysis \& Policy 12 (2): 1-42. DOI: 10.1515/1935-1682.3347.

Easterlin, R. 1974. “Does Economic Growth Improve the Human Lot? Some Empirical Evidence." In Nations and Households in Economic Crowth: Essays in Honor of Moses Abramovitz, edited by R. David, and R. Reder, New York: Academic Press.

Engbom, N., E. Detragiache, and R. Faezeh 2015. The German Labor Market Reforms and Post-Unemployment Earnings. IMF Working Paper WP/15/162.

Frick, J.R., S.P. Jenkins, D. R. Lillard, O. Lipps, and M. Wooden. 2007. “The Cross-National Equivalent File (CNEF) and Its Member Country Household Panel Studies." Schmollers Jahrbuch 127: 627-54. http://www.diw.de/sixcms/detail.php/77260.

Frick, J.R., S.P. Jenkins, D. R. Lillard, O. Lipps, and M. Wooden. 2008. “Die internationale Einbettung des Sozio-oekonomischen Panels (SOEP) im Rahmen des Cross-National Equivalent File (CNEF)." Vierteljahrshefte zur Wirtschaftsforschung 77: 110-29. http://www.diw.de/sixcms/detail.php?id=diw_01.c.86719.de.

Cershuny, ]. 2000. Changing Times: Work and Leisure in Postindustrial Society. Oxford and New York: Oxford University Press.

Cottschalk, P. 1997. "Inequality, Income Growth, and Mobility: The Basic Facts.” The Journal of Economic Perspectives 11 (2): 21-40.

Cottschalk, P., and R. Moffitt. 2002. "Trends in the Transitory Variance of Earnings in the United States." Economic Journal 112: C68-C73. DOI: 10.1111/1468-0297.00025.

Cottschalk, P., and R. Moffitt. 2009. “The Rising Instability of U.S. Earnings." The Journal of Economic Perspectives 23 (4): 3-24.

Cottschalk, P., and E. Spolaore. 2002. “On the Evaluation of Economic Mobility." The Review of Economic Studies 69 (1): 191-208.

Crimm, M. 2007. "Removing the Anonymity Axiom in Assessing Pro-Poor Crowth." Journal of Economic Inequality 5 (2): 179-97.

Hardy, B., and J.P. Ziliak. 2013. “Decomposing Trends in Income Volatility: The 'Wild Ride' at the Top and Bottom.” Economic Inquiry 52 (1): 459-76.

Hardy, B.L. 2017. “Income Instability and the Response of the Safety Net." Contemporary Economic Policy 35: 312-30.

Hill, HD., J. Romich, Mattingly, M]., S. Shamsuddin, H. Wething, et al. 2017 (9). “An Introduction to Household Economic Instability and Social Policy." Social Service Review 91 (3): 371-389. DOI: 10.1086/694110.

Hopkins, E. 2008. “Inequality, Happiness and Relative Concerns: What Actually Is Their Relationship?" The Journal of Economic Inequality $6:$ 351-72.

Jäntti, M., and S.P. Jenkins. 2015. “Income Mobility," in Handbook of Income Distribution,. edited by A.B. Atkinson, and F. Bourguignon Vol. 2. North Holland: Elsevier Chapter 12

Jenkins, S.P. 2011. Changing Fortune: Income Mobility and Poverty Dynamics in Britain. Oxford: Oxford University Press 
Jenkins, S.P., and P. Van Kerm. 2006. "Trends in Income Inequality, Pro-Poor Income Growth, and Income Mobility." Oxford Economic Papers 58: 531-48.

Maasoumi, E., and M. Trede. 2001. “Comparing Income Mobility in Germany and the United States Using Generalized Entropy Mobility Measures." Review of Economics and Statistics 83 (3): 551-59.

Moffitt, R., and S. Zhang. 2018. "Income Volatility and the PSID: Past Research and New Results." AEA Papers and Proceedings 108: 277-80.

Moffitt, R.A., and P. Gottschalk. 2012. "Trends in the Transitory Variance of Male Earnings Methods and Evidence." Journal of Human Resources 47 (1): 204-36.

Myck, M., R. Ochmann, and S. Qari 2009. Dynamics of Earnings and Hourly Wages in Cermany. DIW-Discussion Paper, No. 929.

OECD. 2016a. OECD Employment Outlook. Paris: OECD. http://www.oecd.org/els/emp/oecdindicatorsofemploymentprotection.htm.

OECD. 2016b. Tax and Benefit Systems: OECD Indicators. Paris: OECD. http://www.oecd.org/els/benefits-and-wages.htm.

Palmisano, F. (2018). "Evaluating Patterns of Income Growth when Status Matters: A Robust Approach." Review of Income and Wealth 64 (1): 147169. https://doi.org/10.1111/roiw.12272.

Palmisano, F., and V. Peragine. 2015. "The Distributional Incidence of Growth: A Social Welfare Approach." Review of Income and Wealth 61 (3): 440-64.

Palmisano, F., and D. Van de Gaer. 2016. "History-Dependent Growth Incidence: A Characterization and an Application to the Economic Crisis in Italy." Oxford Economic Papers 68 (2): 585-603.

Peichl, A., N. Pestel, and H. Schneider. 2012. “Does Size Matter? The Impact of Changes in Household Structure on Income Distribution in Germany." Review of Income and Wealth 57: 118-41.

Rodrik, D. 1998. “Why Do More Open Economies Have Larger Governments?” Journal of Political Economy 106: $997-1032$.

Rohde, N., K. Tang, and D.P. Rao. 2014. "Distributional Characteristics of Income Insecurity in the U.S., Germany, and Britain." Review of Income and Wealth 60: S159-S176.

Sen, A. 1976. "Poverty: An Ordinal Approach to Measurement." Econometrica XLIV: 219-31.

Shin, D., and G. Solon. 2011. "Trends in Men's Earnings Volatility: What Does the Panel Study of Income Dynamics Show?" Journal of Public Economics 95 (7): 973-82.

Sologon, D., and C. O'Donoghue. 2014. "Shaping Earnings Insecurity: Labor Market Policy and Institutional Factors." Review of Income and Wealth 60: 205-32.

Van Kerm, P. 2004. “What Lies behind Income Mobility? Reranking and Distributional Change in Belgium, Western Germany and the USA.” Economica 71: 223-39.

Van Kerm, P. 2009. "Income Mobility Profiles." Economic Letters 102: 93-95.

Yitzhaki, S. 1979. "Relative Deprivation and the Gini Coefficient." The Quarterly Journal of Economics 93 (2): 321-24. 